\title{
Examination of Athletic Trainer's Perceptions on Mentoring Relationships
}

Nicole Anne Wilkins

University of St. Augustine for Health Sciences

DOI: https://doi.org/10.46409/sr.NZNZ8294

Follow this and additional works at: https://soar.usa.edu/dissertations

Part of the Rehabilitation and Therapy Commons

\section{Recommended Citation}

Wilkins, N. A. (2018). Examination of Athletic Trainer's Perceptions on Mentoring Relationships. [Doctoral project, University of St Augustine for Health Sciences]. SOAR @ USA: Student Dissertations Collection. https://doi.org/10.46409/sr.NZNZ8294 
Examination of Athletic Trainer’s Perceptions on Mentoring Relationships

A dissertation submitted in partial fulfillment of the requirements for the degree of Doctor of Education at the University of St. Augustine for Health Sciences

Nicole Anne Wilkins, MS, LAT, ATC 


\section{Abstract}

Keywords: mentor, protégé, gender, retention, athletic training 
WE, THE UNDERSIGNED MEMBERS OF THE COMMITTEE, HAVE APPROVED THIS DISSERTATION IN PARTIAL FULFILLMENT OF THE REQUIREMENTS FOR THE DEGREE

DOCTOR OF EDUCATION

\section{Examination of Athletic Trainer's Perceptions on Mentoring Relationships}

By:

Nicole Anne Wilkins

COMMITTEE MEMBERS

Chuck Kimmel, MA, LAT, ATC

Contributing Faculty Member, Athletic Training

University of St. Augustine for Health Sciences

Jordan Utley, Ph.D., LAT, ATC

Program Director, Master of Health Science

Associate Professor

University of St. Augustine for Health Sciences

ACCEPTED AND APPROVED ON BEHALF OF THE UNIVERSITY

Cindy Mathena, Ph.D., OTR/L

Dean of Post Professional Studies

University of Saint Augustine for Health Sciences 


\section{Dedication}

This dissertation is dedicated to my personal mentors that have guided me throughout my career. Sara Brown, Jerry Greeson and Dr. Jeff Bonacci: thank you for your unending support and guidance. I would not be the clinician and educator I am today without your help. You all took a chance on me when I didn’t know what I was doing, or what my potential could be. I hope I’ve made you all proud.

I would also like to dedicate this dissertation to my family: my beloved husband, Chris, my parents, Bob \& Linda Reimers, and my grandmother, Rosemary Granato. Words cannot express how much I love and appreciate you all. Thank you for all the sacrifices you made for me to achieve this dream, and for your continual encouragement in what seemed like a neverending process.

Lastly to my “family”: Michael \& Sandra, Laura \& Pete, Chris \& Billy, Matt \& Jamie, my “sister”, Brie, and my favorite “sons”, Grant and Ty. I love you all more than you will ever know or could ever express in words. Thank you for being my people, my tribe, and most importantly, my friends. 


\section{Acknowledgements}

This dissertation would not be possible without the guidance and encouragement from my committee, Mr. Chuck Kimmel and Dr. Jordan Utley. Without your patience, expertise, and wisdom, this process would never have come to fruition. I am forever grateful to you both and your commitment to higher education and the profession of athletic training. Thank you for challenging me and pushing me beyond what I ever thought could be possible. I would also like to thank the University of St. Augustine Doctor of Education Faculty, specifically Dr. Shannon Groff and Dr. Cindy Mathena. I admire you both immensely and am so thankful for all that you have taught me on this journey, both in and out of the classroom. Lastly, to the athletic training staff at St. Edward's University, thank you for your flexibility and support through this process. I am proud to not only call you my colleagues, but more importantly, my friends. 
Table of Contents

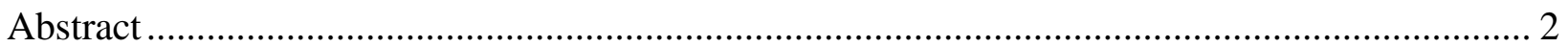

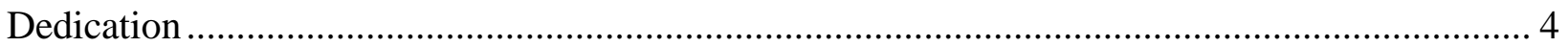

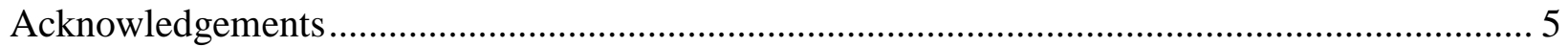

List of Tables .

Error! Bookmark not defined.

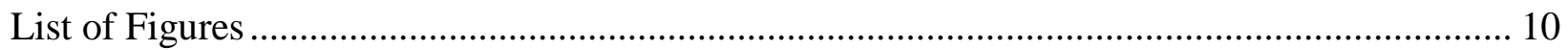

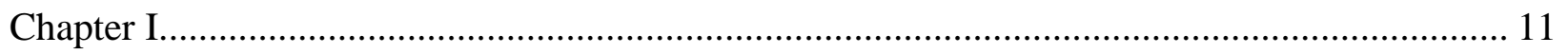

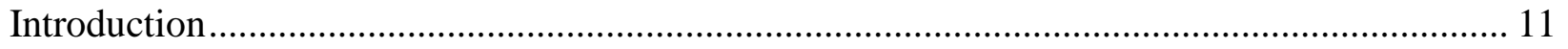

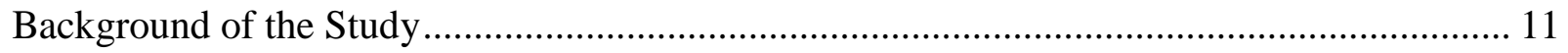

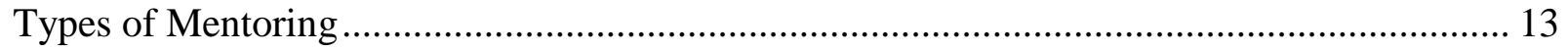

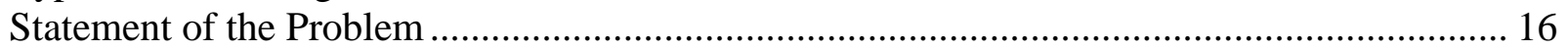

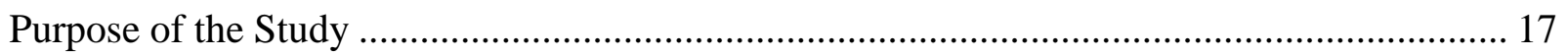

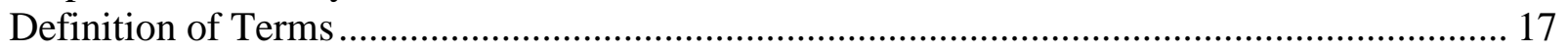

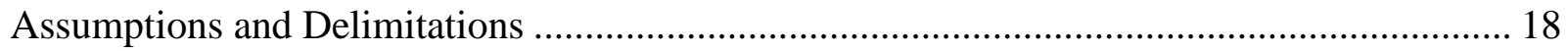

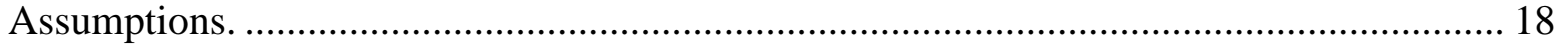

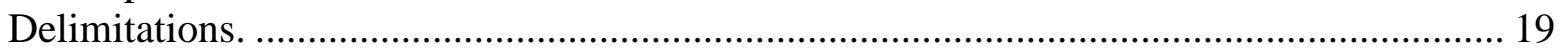

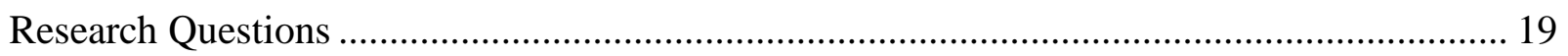

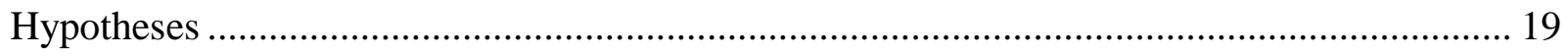

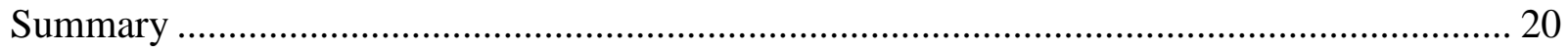

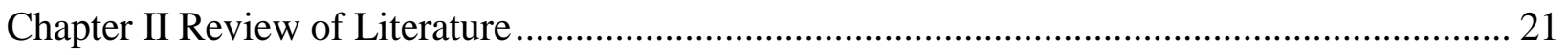

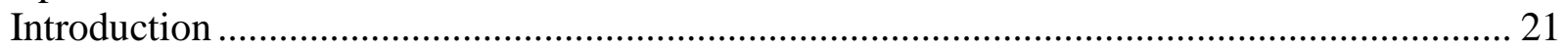

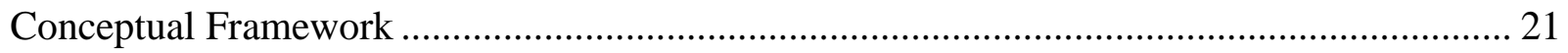

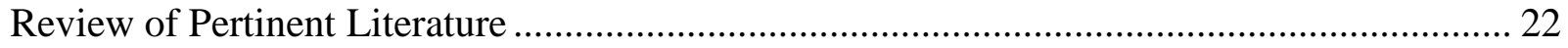

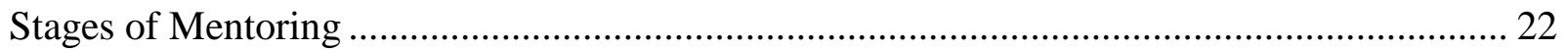

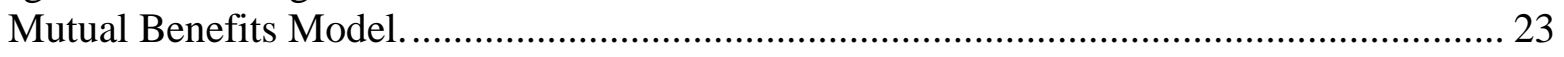

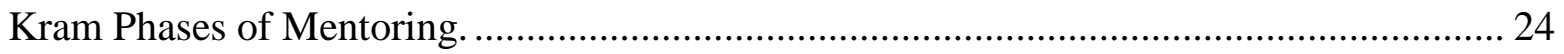

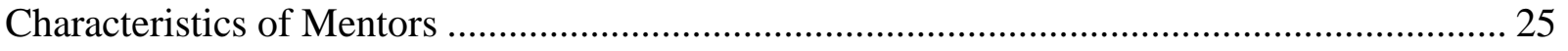

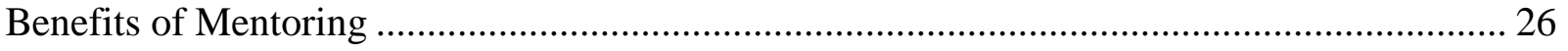

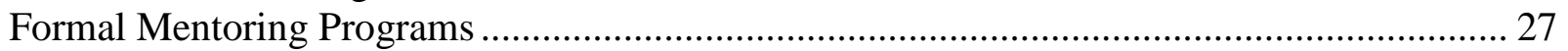

Peer Mentoring \& Informal Mentoring......................................................................... 28

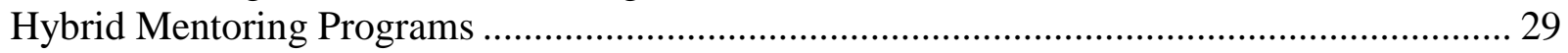

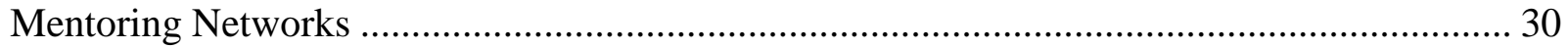

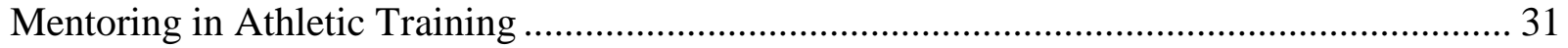

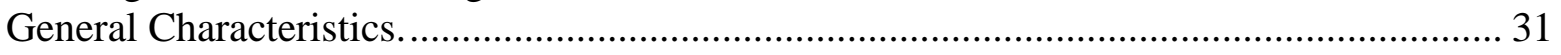

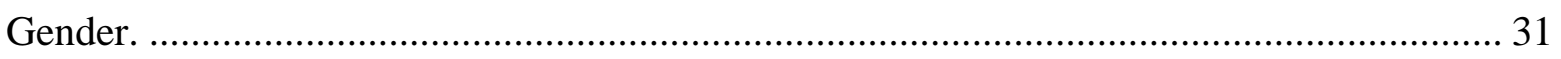

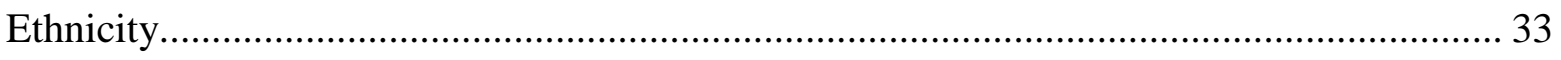

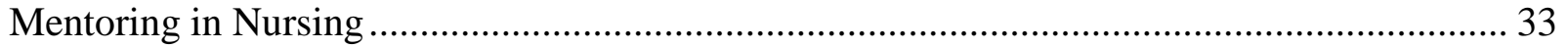

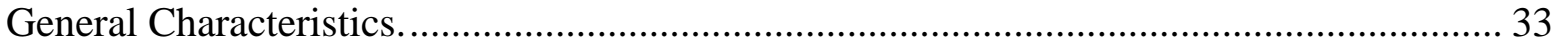

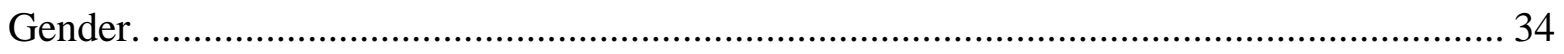

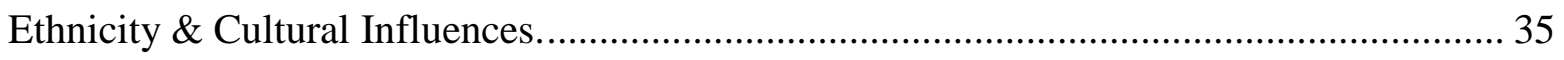




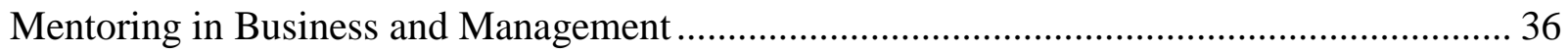

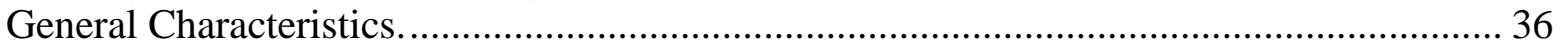

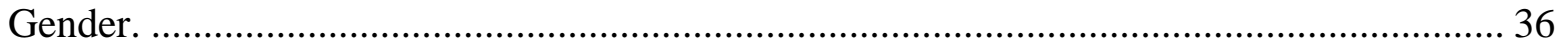

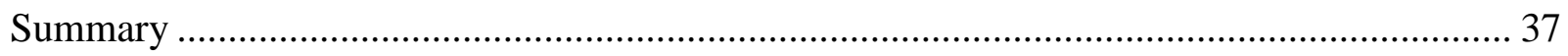

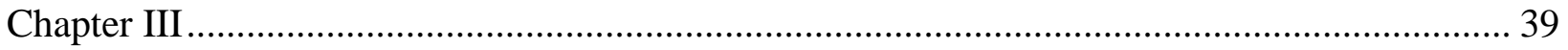

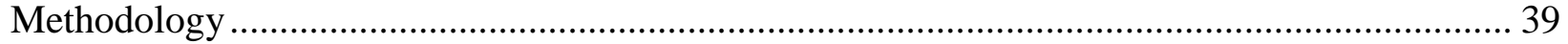

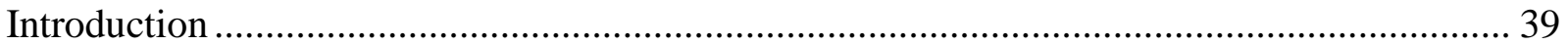

Review of the Purpose of Study................................................................................ 40

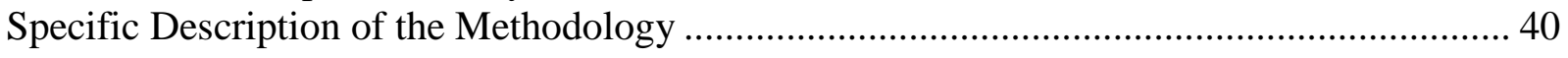

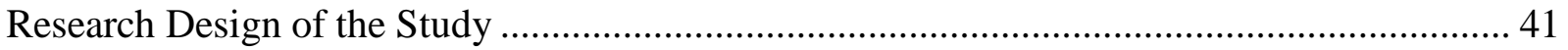

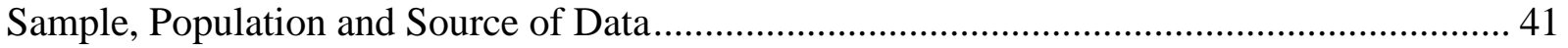

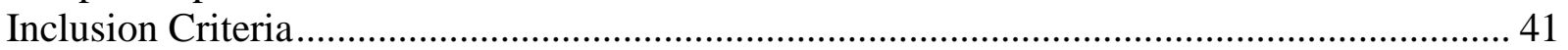

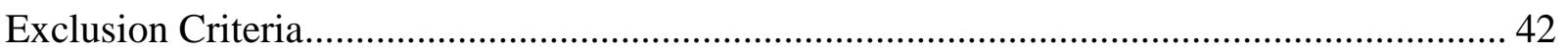

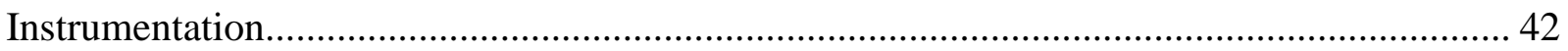

Dependent and Independent Variables..................................................................... 43

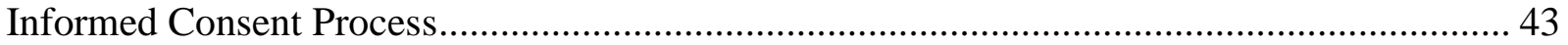

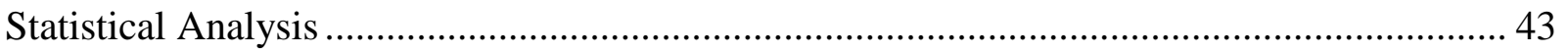

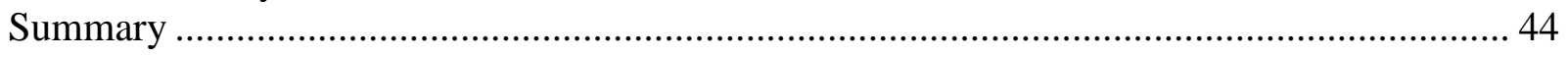

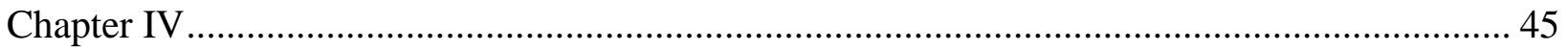

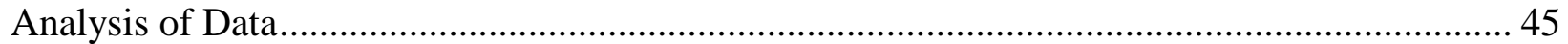

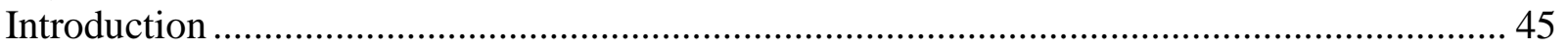

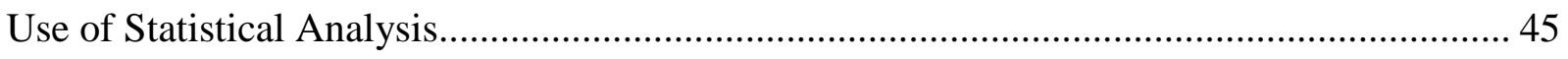

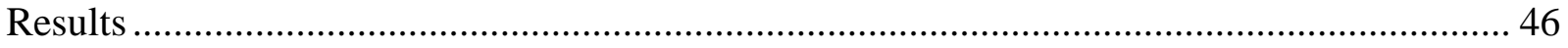

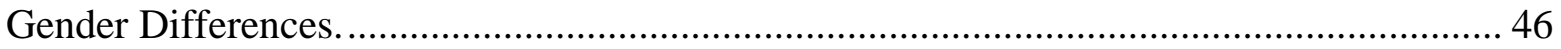

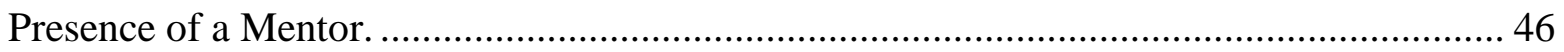

Effects of Similar Gender, Age and Ethnicity .......................................................... 46

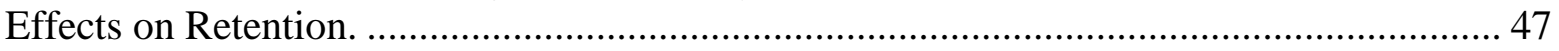

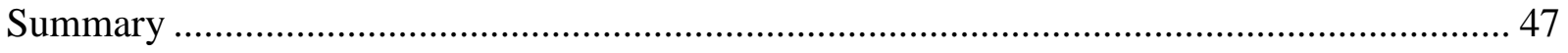

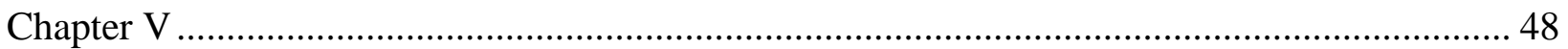

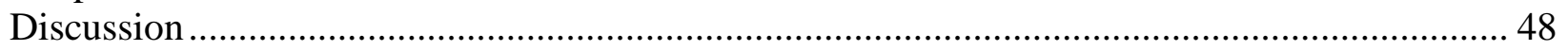

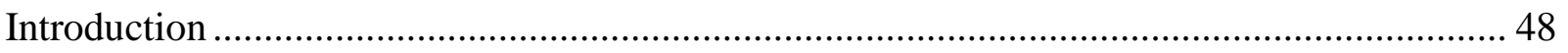

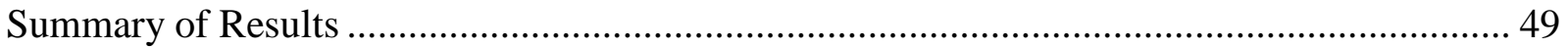

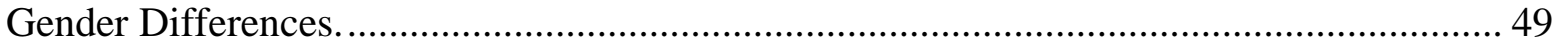

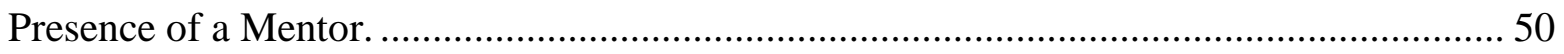

Effects of Similar Gender, Age and Ethnicity ............................................................ 50

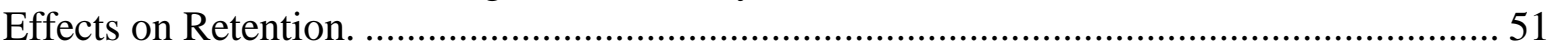

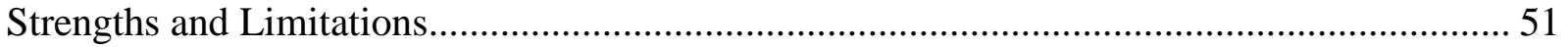

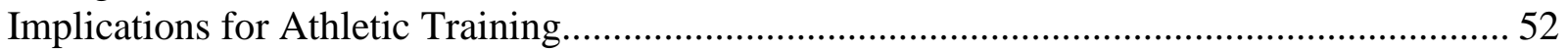

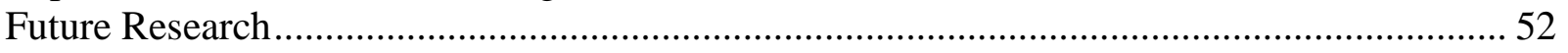

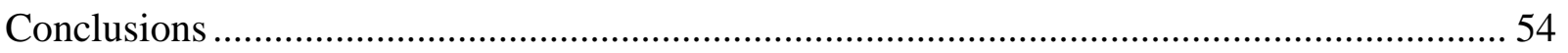

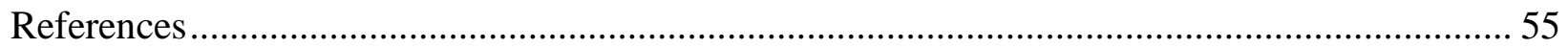




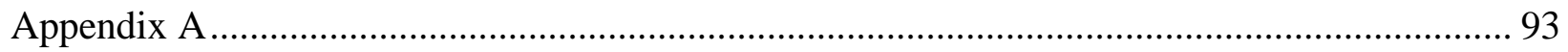

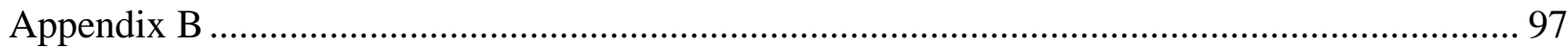


List of Tables

Table 1.1 Demographics: Age and Gender of Respondents.............................65

Table 1.2 Demographics: Ethnicity............................................66

Table 1.3 Demographics: State of Employment...................................67

Table 2 Cronbach's Alpha for ATSPME Subscales.................................68

Table 3.1 ANOVA Table for ATSPME Subscales Based on Respondent Gender..........69

Table 3.2 Descriptive Statistics for ATSPME Subscales Based on Respondent Gender.....70

Table 3.3 ANOVA Table for Individual Questions Based on Respondent Gender..........71

Table 3.4 Descriptive Statistics for ATSPME Individual Questions Based on Respondent

Gender......................................................... 73

Table 4 Frequency Distribution for Current and Past Mentor Split by Gender............76

Table $5 \quad$ Reported Roles of Current and Previous Mentors............................77

Table 6.1 Descriptive Statistics for Similar Demographic Characteristics Split by Gender.78

Table 6.2 Frequency Distribution for Likert Scaled Responses: Similar Ethnicity...........79

Table 6.3 Frequency Distribution for Likert Scaled Responses: Similar Age...............80

Table 6.4 Frequency Distribution for Likert Scaled Responses: Similar Gender............81

Table 7.1 Descriptive Statistics for Perceived Effect on Retention Split by Gender........82

Table 7.2 Frequency Distribution for Likert Scaled Responses: Effect on Retention........83 


\section{List of Figures}

Figure 1 ATSPME Subscale Responses Split by Gender............................84

Figure 2.1 ATSPME Q2 Responses Split by Gender..................................85

Figure 2.2 ATSPME Q3 Responses Split by Gender...................................86

Figure 2.3 ATSPME Q23 Responses Split by Gender................................87

Figure 2.4 ATSPME Q25 Responses Split by Gender................................88

Figure 3.1 Importance of Similar Ethnicity Split by Gender............................89

Figure 3.2 Importance of Similar Age Split by Gender................................90

Figure 3.3 Importance of Similar Gender Split by Gender..............................91

Figure 4 Perceived Effects of Mentoring on Retention Split by Gender.................92 


\section{Chapter I}

\section{Introduction}

\section{Background of the Study}

Young health professionals often learn the essential skills for success in their profession by listening to, imitating, and modeling the behaviors of more experienced members within the professional community (Bandura, 1977). These modeled behaviors, in conjunction with the relationships that develop, form the foundation of a young professionals' values and attitudes (Pitney \& Ehlers, 2004). Mentoring relationships are defined across contemporary health professions literature using the terms mentor and protégé to differentiate the roles within the relationship. These relationships develop between more experienced mentors and less experienced protégés, to foster growth of the protégé in their chosen career (Mazerolle, Walker, \& Thrasher, 2015; Mitchell, Ely, \& Ragins, 2015; Nottingham, Mazerolle, \& Barrett, 2017).

The concept of mentoring is derived from Homer’s The Odyssey (Goitian, 2016; Shafer, 2009; Shea, 1992; Vatan \& Temnel, 2016). In the epic poem, while Odysseus is away fighting in the Trojan War, he entrusts the care of his household and family to Mentor, a teacher, friend, and advisor to his son, Telemachus (Shea, 1992). After the war as Odysseus is exiled, Telemachus and the Goddess Athena, in the form of Mentor, search for Odysseus. Homer uses Mentor as a representation of the duality in life: the push and pull, yin and yang, goal and path (Black, 2017). This duality forms the foundation of contemporary mentoring relationships, in which mentors' challenge and support, lead and guide, and push and facilitate the growth of their protégés.

During the Middle Ages, the practice of mentoring evolved into apprenticeships (Block, et al., 2005), and health professions, such as athletic training, still utilize aspects of structured apprenticeships for those that are entering the profession in the form of graduate assistantships 
(Mazerolle, Clines, Eason, \& Pitney, 2015). Graduate assistantships are utilized as transition to practice into the profession of athletic training, and serve to bridge the gap from undergraduate student to professional (Mazerolle, Clines, et al., 2015; Mazerolle, Walker, et al., 2015). As a graduate assistant, newly certified practitioners earn their master's degree while working as practicing athletic trainers under the supervision of one or more experienced individuals. This allows for continued growth and development of the individual's skills, as well as more extensive clinical mentoring beyond that of pre-professional preceptor-student mentoring relationships (Mazerolle, Clines, et al., 2015; Mazerolle, Gavin, Pitney, Casa, \& Burton, 2012; Mazerolle, Walker, et al., 2015; Walker, Thrasher, \& Mazerolle, 2016).

Graduate assistantships also include professional socialization into athletic training, which is the process by which an individual begins to gain insight into their chosen career and learns professional behaviors associated with success (Mazerolle, Bowman, \& Dodge, 2014; Mazerolle, Clines, et al. 2015; Mazerolle et al. 2012). Professional socialization can be divided into two independent phases: the anticipatory phase and the organizational phase (Mazerolle et al., 2014; Mazerolle, Clines, et al., 2015). In the anticipatory phase, the individual begins to gain knowledge and information about their chosen career, and imagines their ideal role within the profession (Mazerolle, Clines, et al. 2015; Mazerolle et al., 2012). The individual gains this information through personal experiences such as informal shadowing/observational opportunities in a clinical setting (Mazerolle, Clines, et al. 2015; Mazerolle et al., 2012). The informal nature of this phase can serve as introduction into the intricacies of the profession, as well as ignite future interest in continuing in the profession long-term (Mazerolle et al., 2014; Mazerolle et al., 2012). The second phase is the organizational phase, in which the individual enters the profession and begins to assume the roles and responsibilities afforded within the 
given field (Mazerolle et al., 2014; Mazerolle, Clines, et al., 2015). This phase continues across the duration of the individual's career, as they acquire new knowledge, skills, and experiences (Mazerolle, Clines, et al., 2015). Mentoring plays a crucial role in the organizational phase of professional socialization. During this phase, the protégé seeks guidance from the mentor to reinforce professional roles, such as skills advancement, learning opportunities, and networking (Mazerolle et al., 2012).

This concept of professional socialization is not isolated to the practice of clinical athletic training. Bowman, Klossner, and Mazerolle (2017) and Mazerolle, Barrett, and Nottingham (2016) explored the significance of professional socialization, specifically within the profession of athletic training education. Professional socialization in education can be divided into two phases: professional and organizational (Mazerolle, Barrett, et al., 2016). The professional phase focuses on the development of technical skills related to teaching, research and service, whereas the organizational phases focuses on the expectations specific to the individual's institution (Mazerolle, Barret, et al., 2016). During these phases, senior faculty members often serve in mentoring roles for junior faculty by explaining the intrinsic and extrinsic demands of their new role (Bowman et al., 2017). Relationships with senior faculty become increasingly important throughout the tenure process, as faculty mentors provide insight into the intricacies and expectations of the organization (Mazerolle, Barret, et al., 2016; Schrodt, Cawyer, \& Sanders, 2003). Types of mentoring relationships and their utilization in practice will be evaluated in subsequent sections

\section{Types of Mentoring}

Shafer (2009) outlines the six roles of a mentor as "teacher, sponsor, adviser, agent, role model, and confidant” (p. 161). These characteristics and roles are common across health 
professions, such as nursing (Al-Hamdan, Fowler, Bawadi, Norrie, Summers, \& Dowsett, 2014; Block, Claffey, Korrow, \& McCaffrey, 2005; Vatan \& Temel, 2016), athletic training (Mazerolle, Eason, Nottingham, \& Barrett, 2016; Nottingham et al., 2017; Pitney \& Ehlers, 2004), physical therapy (Yoon et al., 2017), and also extend into the areas of business (Balu \& James, 2017), radiologic technology (Yates, 2017), academic medicine (DeCastro, Sambuco, Ubel, Stewart \& Jagsi, 2013; Stamm \& Buddeberg-Fischer, 2011), education (Black, 2017; Crisp \& Cruz, 2009; Pogrund \& Cowamn, 2013) and the practice of medicine (Saperstein, Vera \& Firnhaber, 2012).

These characteristics and values of a mentor provide the underpinnings of mentoring relationships. Within mentoring research, two predominant mentoring styles emerge: formal mentoring and informal mentoring. Formal mentoring is defined by structured relationships (Vatan \& Temel, 2016); this type of mentoring has been found effective in addressing issues of gender and ethnic diversity (Woolnough \& Fielden, 2014). Programs such as the Research Faculty Mentoring Program through the National Athletic Trainers’ Association (National Athletic Trainers’ Association [NATA] Research Foundation, 2018), the Wisconsin Nurse Residency Program (Bratt, 2009), the Challenging Perceptions nursing program in the United Kingdom (Woolnough \& Fielden, 2014), and the Flying Start program for nurses within the National Health Service (NHS) in the United Kingdom (Solowiej, Upton, \& Upton, 2010), all serve as formal mentoring programs that target the specific needs of those individuals within the profession.

Woolnough and Fielden (2014) examined the impact of implementing a career development and mentoring program for female nurses working in the mental health sector. The authors found that those that had access to the formal mentorship program had significantly 
higher rates of promotion within their jobs, had an increase in self-confidence and self-esteem, reported a perceived increase in leadership effectiveness, and were able to highlight multiple examples of personal growth and development based on the techniques they had learned (Woolnough \& Fielden, 2014). Additionally, Solowiej, Upton \& Upton (2010) found that newly qualified practitioners enrolled in the Flying Start program had an increase in self-value as a practitioner, and the program was beneficial to their career development. Formal programs, such as those listed, effectively target specific needs and populations within the profession.

Within formal mentoring programs, mentors and protégés are often matched based on similar interests or goals. Often, these similar interests are based on research interests or career paths (Barrett, Mazerolle, \& Nottingham, 2017; Cellini, Serwint, D’Alessandro, Schulte, \& Osman, 2017; Nottingham et al., 2017). In health professions education, formal mentoring may take the shape of an assigned preceptor or supervisor within the student's clinical rotation (Mazerolle, Clines, et al., 2015; Mazerolle, Walker, et al., 2015; Nottingham et al., 2016; Walker et al., 2016). It is during this formal mentoring and socialization process that protégés obtain the knowledge and skills needed to be successful in that setting (Cellini et al., 2017; Mazerolle et al., 2014), as well as receive guidance and support from their mentor (Walker et al., 2016).

Conversely, informal mentoring is unstructured in nature (Vatan \& Temel, 2016) and often occurs between peers, colleagues, or supervisors (Mazerolle et al, 2014; Mazerolle, Walker et al., 2015; Nottingham et al., 2016; Walker et al., 2016). Health professions benefit from this unstructured nature, as mentoring relationships can form organically and may develop into longer lasting relationships than structured pairings (Nottingham et al., 2016), as well as ensure better chemistry between the pairing (Yamda, Slanetz, \& Boiselle, 2014). This unstructured relationship, especially in the form of peer mentoring, is essential in aiding young professionals 
transition to practice by providing guidance and support (Walker et al., 2016), and assisting in the socialization process (Mazerolle et al., 2014). As reported by Mazerolle, Clines, et al. (2015) and Walker et al. (2016), newly credentialed athletic trainers utilize peer mentoring before contacting their supervisors, as there is a mutual understanding of the workload demands in the setting. Whether through formal or informal practices, mentoring relationships are vital in the development of the protégé, and especially for those transitioning into new roles of practice.

\section{Statement of the Problem}

Retention of high caliber and competent athletic trainers in the profession has become an increasingly greater concern within athletic training (Barrett, Mazerolle, \& Eason, 2016). Long work hours, issues with work-life balance, feeling underappreciated at work and receiving lower wages as compared to other health professionals have all been cited as reasons for departure from the profession (Barrett et al., 2016; Eason, Mazerolle \& Goodman, 2014; Mazerolle et al., 2012). Little research has been conducted on mentoring relationships that occur in athletic training clinical practice; articles on mentoring in athletic training focus on the formal and informal mentoring relationships that occur within professional athletic training educational programs (Burningham, Deru \& Berry, 2010; Mazerolle, Barrett, Eason \& Nottingham, 2017; Mazerolle \& Dodge, 2015; Mazerolle, Eason, et al., 2016; Pitney \& Ehlers, 2004; Pitney, Ehlers \& Walker, 2006). To date, there are no formal mentoring or transition to practice programs reported in athletic training literature (Walker et al., 2016). Previous research has also identified a gap in identifying differences in perceptions on mentoring relationships based on gender (Mazerolle et al., 2017). To aid in the retention of high caliber athletic trainers in the profession, the development of effective mentoring relationships and their influences on retention need to be examined. 
Due to the lack of research within the profession, the field of athletic training must look to other health professions, such as nursing and medicine, to model best-practice mentoring relationships to address retention concerns. Nursing literature has focused on the success of formal mentoring programs, as previously examined. While there currently is no formal clinical mentoring program in place for athletic trainers, key tenets of these formal programs from other professions can be utilized in examining current practices related to mentoring within athletic training.

\section{Purpose of the Study}

The purpose of this quasi-experimental study is to examine the presence of mentoring relationships, as well as identify characteristics of effective mentors, within the secondary school setting. The study focused on District Six of the National Athletic Trainers' Association (NATA), which is comprised of the states of Texas and Arkansas. Quantitative analysis was used to examine respondents' mentors, as well as the values and personal characteristics deemed most significant in mentoring relationships. With the shift in educational standards brought about by the Commission on Accreditation of Athletic Training Education (CAATE), the traditional graduate assistant route will cease to exist in its current iteration, and will result in young professionals transitioning to practice immediately upon completion of their academic program (Commission on Accreditation on Athletic Training Education [CAATE], n.d.).

\section{Definition of Terms}

- Formal Mentorship: programs are structured in nature and are usually targeted to specific populations. Examples of formal mentorship programs include: Challenging Perceptions, Flying Start, and the Wisconsin Nurse Residency Program. 
- Graduate Assistantship (GA): “A paid, but temporary, employment position. This position may or may not include employee benefits and is guided by college/university policy and applicable legislation for employing a graduate assistant. The primary objective is to financially support the student's academic studies” (NATA, n.d.b.).

- Informal Mentorship: programs that are less structured in nature and often form between peers, colleagues or supervisors.

- Mentor: “a wise and trusted counselor or teacher; an influential senior sponsor or supporter” (Mentor, n.d.); a role model. Mentors may include teachers, colleagues, or peers.

- National Athletic Trainers’ Association (NATA): “The professional membership association for certified athletic trainers and others who support the athletic training profession. The mission of the National Athletic Trainers' Association is to represent, engage and foster the continued growth and development of the athletic training profession and athletic trainers as unique health care providers” (NATA, n.d.a.).

- Protégé: an individual, often with less experience, that is under the guidance of a mentor.

- Retention: to remain in one's chosen profession, in this instance, athletic training.

- Transition to Practice: “The ongoing personal and professional growth as the employee adapts to the job” (Walker et al., 2016).

\section{Assumptions and Delimitations}

Assumptions. It was assumed that the sample population was representative of the athletic training profession's attitudes towards mentoring relationships. It was assumed that all 
respondents fully understood the questions on the survey, as well as the pertinent definitions listed at the beginning of the survey. The data was collected voluntarily and anonymously online; therefore, it was assumed that participants answered the questions honestly and accurately. The 5-point Likert responses used in this survey assumed that each participant had an opinion surrounding each item, including a neutral option.

Delimitations. The sample population was purposefully limited to secondary schools within District Six of the NATA. Unlike Arkansas, secondary schools within the state of Texas often employ two athletic trainers, one of each gender, to provide medical coverage to the sports on their campus. The survey was distributed through the NATA with the set population parameters, which is not inclusive of all athletic trainers working in the state of Texas.

\section{Research Questions}

RQ1: Do female athletic trainers in the secondary setting value interpersonal characteristics of mentoring relationships more compared to their male counterparts?

RQ 2: Do athletic trainers in the secondary school clinical setting identify as having a mentor?

RQ 3: Does similar gender, age, and ethnicity in the mentor-protégé relationship result in more positive perceptions of mentoring effectiveness?

RQ 4: Can effective mentoring have an effect on a protégé’s retention in their profession?

\section{Hypotheses}

Hypothesis 1: Significant differences exist between genders in the value of interpersonal characteristics of mentoring relationships.

Hypothesis 2: Athletic trainers within the secondary setting will identify as having a mentor. Hypothesis 3: No differences exist in the perception of mentoring effectiveness based on the similarity of gender, age, or ethnicity in the mentor-protégé relationship. 
Hypothesis 4: The perception of effective mentoring will positively affect perceived retention within the protégé's profession.

\section{Summary}

The process of mentoring is important in any profession; however, it is especially important in health professions such as athletic training. While much of the research has been done examining the attitudes of mentoring from a student perspective in athletic training (Barrett et al., 2016; Burnigham et al., 2010; Klossner, 2008; Mazerolle et al., 2017; Mazerolle et al., 2014; Mazerolle, Bowman, et al., 2015; Mazerolle, Dodge, et al., 2015; Mazerolle, Eason, et al., 2016; Mazerolle et al., 2012; Pitney \& Ehlers, 2004; Pitney et al., 2006), no research has currently been done on mentoring relationships from the practicing clinician perspective. The aim of this study was to examine the attitudes and perceptions of mentoring relationships of those individuals practicing clinically within the secondary school setting. This study discusses the key characteristics of effective mentoring relationships, the usefulness of mentoring relationships and mentoring networks within health professions, and the efficacy of mentoring relationships for all parties involved. The results of this study intend to explore the various mentoring roles and characteristics of effective mentoring relationships. 


\section{Chapter II}

\section{Review of Literature}

\section{Introduction}

As discussed in Chapter I, mentoring relationships are formed between a more experienced mentor and a less experience protégé, and foster the growth of the protégé in their chosen career (Mazerolle, Walker, et al., 2015; Mitchell et al., 2015; Nottingham et al., 2017). This review aims to: outline the conceptual framework used for the study; discuss the key characteristics of effective mentors; examine the benefits of mentoring for both the mentor and protégé; identify the importance of having a mentoring relationship or mentoring network; and highlight the need for effective mentors across gender and ethnically diverse populations. Research on mentoring relationships within the clinical aspect of athletic training is limited; however, research from other health professions and business will be utilized for comparison.

\section{Conceptual Framework}

The theoretical model that provided the framework for this study is Bandura’s (1977) work on the social learning theory. This theory is rooted in the concept that individuals learn from each other through the processes of observation, imitation and modeling (Bandura, 1977). Heavy emphasis is placed on the observation phase, as Bandura argues that learning occurs through direct observation of other's behaviors, as well as through the positive and negative outcomes associated with those behaviors (Bandura, 1977). During the observation phase, ineffective or negative behaviors, as perceived by the new learner, are rejected in favor of more effective or positive behavior; imitation and modeling occur as the new learner begins to mimic the behaviors of the individual they are observing, especially those that had positive outcomes (Bandura, 1977). The behaviors are then reinforced by the model, by other learners in the 
environment, or by the positive outcomes associated with the behavior; as a result, this reinforcement drives the development of future actions in similar situations (Bandura, 1977).

Social learning theory is evident in athletic training through the process of professional socialization, as novice students and novice members of the professional community look to model positive professional behaviors of those with more experience (Mazerolle, Barrett, et al., 2016; Mazerolle et al., 2014; Mazerolle \& Dodge, 2015; Mazerolle, Walker, et al., 2015; Nottingham et al., 2016). Conversely, Nottingham et al. (2016) report that one-third of the participants in their study identified negative behaviors demonstrated by their mentors that they did not wish to emulate. Identifying both positive and negative behaviors of the mentor provides valuable information to the protégé and becomes the framework of the mentor-protégé relationship (Nottingham et al., 2016).

\section{Review of Pertinent Literature}

The subsequent sections aim to provide a detailed review of the pertinent literature as related to mentoring relationships within health professions. While each health profession utilizes unique approaches to best practices in mentoring, commonalities are observed that address concerns specific to health professions.

\section{Stages of Mentoring}

In conjunction with Bandura’s Social Learning Theory, the mutual benefits model (Zey, 1991) and Kram’s (1983) phases of mentoring are used to develop successful mentoring relationships. These models give both the mentor and protégé structure in which to frame the mentoring relationship, and account for the need for changes in the relationship as both the mentor and protégé grow (Kram, 1983; Zey, 1991). 
Mutual Benefits Model. This model appears in Zey’s (1991) text, and while traditionally utilized in business mentoring, it also appears in contemporary mentoring research in nursing (Jakubik, 2008). The model is comprised of a triad exchange relationship between the mentor, the protégé, and the organization; benefits are transferred back and forth between mentor and protégé, as well as back and forth to the organization (Zey, 1991). Mentors teach and support their protégé, while the protégé helps their mentor do their job by providing information about the organization; this exchange between mentor and protégé influences the organization, and helps to create the culture of the organization (Zey, 1991).

The mutual benefits model has four distinct phases within the mentoring relationship: teaching the protégé, supporting the protégé, marketing and protecting the protégé, and promotion of the protégé (Zey, 1991). The phases are not lock-step, do not always progress from teaching to promotion, and the mentor can perform any of these functions at any point in the mentoring relationship (Zey, 1991). Jakubik (2008) reports that research on nursing mentoring relationships has predominately focused on the first two phases of Zey’s model, and components of the model appear in athletic training literature (Eason et al., 2014; Mazerolle, Eason, et al., 2016; Mazerolle, Walker, et al., 2015; Walker et al., 2016).

During the teaching phase, the mentor is responsible for teaching the protégé about the organization, as well as providing the knowledge and skills for the protégé to be successful in the organization (Zey, 1991). In the supporting phase, mentors aid in building the protégé’s confidence, and acts as a resource to discuss issues such as work-life balance and the stressors associated with the job (Zey, 1991). During the marketing and protection phase, the mentor provides access to higher level resources to the protégé, and begins to endorse the protégé to more senior level management (Zey, 1991). Lastly, in the promotion phase, the mentor either 
directly or indirectly helps their protégé reach the next level in their career, which includes helping the protégé obtain publication opportunities, new certifications, and expanding their job function to incorporate new duties (Jakubik, 2008; Zey, 1991).

While not explicitly stated, components of the four phases are found throughout athletic training mentoring literature. Mazerolle, Eason, et al. (2016) found that athletic training students in their study sought out mentors for career guidance and support, and relied on mentors to model positive behaviors regarding creating work-life balance. Eason et al. (2014) echoed the importance of mentors in establishing work-life balance, but also state the importance of mentoring relationships in career advancement of the protégé. Lastly, Mazerolle, Walker, et al. (2015) and Walker et al. (2016) stress the influence mentoring relationships have on the transition to practice. The mutual benefits model may be especially helpful in the transition to practice, as newly credentialed athletic trainers learn the components of professional socialization, as well as organizational socialization (Mazerolle, Walker, et al., 2015; Walker et al., 2016).

Kram Phases of Mentoring. Kram’s (1983) model is comprised of four predictable phases in mentoring relationships: initiation, cultivation, separation, and redefinition (Mazerolle, Clines, et al., 2015; Mazerolle, Eason, et al., 2016; Pitney \& Ehlers, 2004; Yates, 2017). In the initiation phase, the protégé, seen as an apprentice, projects desires of admiration for their mentor, and in return, is validated by their mentor who creates an inviting and supportive space for the protégé (Kram, 1983). Mentors begin to establish the relationship with the protégé, and look for ways to provide developmental opportunities to the protégé (Kram, 1983). In the cultivation stage, the emotional bond is strengthened between mentor and protégé, creating a greater sense of mutual benefit for both individuals (Kram, 1983). The protégé is now viewed as 
more of a colleague and peer, and the mentoring relationship peaks during this phase (Kram, 1983). The separation phase is reached when there is a significant change in the mentoring relationship, typically occurring as the protégé begins to become more autonomous (Kram, 1983). Both mentor and protégé recognize that the mentoring relationship is no longer needed in its previous form and must evolve (Kram, 1983; Mazerolle, Clines, et al., 2015). The last phase is redefinition, in which the mentoring relationship ends or continues as equals, rather than in the hierarchy of mentor and protégé (Kram, 1983; Mazerolle, Clines, et al., 2015). Most importantly, this model reflects the change in dynamic in the mentoring relationship, especially in transition to practice, as the mentoring relationship moves from a hierarchical relationship to that of peer to peer (Mazerolle, Clines, et al., 2015).

\section{Characteristics of Mentors}

Across health professions research, several universal characteristics emerge in effective mentoring relationships. These traits include: establishment and professional experiences within the profession (Al-Hamdan et al., 2014; Ferguson, 2011; Yates, 2017); strong communication skills (Barrett, Mazerolle \& Nottingham, 2017; Burningham et al., 2010; Gray \& Smith, 2000; Mazerolle, Bowman, \& Klossner, 2015; Nottingham et al., 2016; Pitney et al., 2006); commitment and desire to the future of the profession (Al-Hamdan et al., 2014; Bowman, Mazerolle, \& Dodge, 2013; Burnighman et al, 2010; Cellini, Serwint, D’Alessandro, Schulte \& Osman, 2017; Ferguson, 2011); the need to facilitate critical thinking (Bowman et al., 2013; Burnighman et al., 2010; Clark \& Casey, 2016; DeCastro et al., 2013; Mazerolle, Eason, et al., 2016; Porgun \& Cowan, 2013; Zanchetta et al., 2017); the need for timely feedback (Clark \& Casey 2016; Gray \& Smith, 2000; Mazerolle, Bowman, et al., 2015; Mazerolle, Walker, et al., 
2015; Pitney et al., 2006); and being accessible to the protégé in timely manner (Barrett, et al., 2017; Burnighman, et al., 2010; DeCastro et al., 2013; Pitney \& Ehlers, 2004).

Strong interpersonal skills are valued by protégé’s engaging in mentoring relationships (Mazerolle et al., 2017; Nottingham et al., 2016; Pitney \& Ehlers, 2004). Trust (Eliot, Leck, Orser \& Mossop, 2006; Ferguson, 2011; Leck \& Orser, 2013; Nottingham et al., 2016; Pitney \& Ehlers, 2004) and professionalism (Al-Hamdan et al., 2014; Burnighman et al., 2010; Gray \& Smith, 2000) are consistently reported as being highly valuable to protégés in health professions literature, as compared to demographic attributes, such as gender and ethnicity (Mazerolle et al., 2017; Pitney \& Ehlers, 2004).

While protégés place more value on the interpersonal attributes of their mentor, there has been research in health professions and business literature on the influence of gender on mentoring relationships (Al-Hamdan et al., 2014; DeCastro et al., 2013; Eason et al., 2014; Eliot et al., 2006; Leck \& Orser, 2013; Shafer, 2009; Siple et al., 2015; Stamm \& Buddeberg-Fischer, 2011; Woolnough \& Fielden, 2014; Yamada, Slanetz, \& Boisele, 2014; Zey, 1991). Ethnic and racial considerations (Al-Hamdan et al., 2014; Siple et al., 2015) have also been investigated. Demographic influences on mentoring relationships are explored in detail in subsequent sections.

\section{Benefits of Mentoring}

Benefits of engaging in a mentoring relationship have been reported throughout health professions literature for both the mentor and protégé. Benefits include: service to the profession (Bowman et al., 2013; Cellini et al., 2017); reciprocal teaching and learning (Bowman et al., 2013; Mazerolle, Bowman, et al., 2015; Nottingham et al., 2016); creating meaningful relationships between mentor and protégé (Bowman et al., 2013; Ferguson, 2011; Leck \& Orser, 2013; Nottingham, et al. , 2017); increased job satisfaction (Cellini et al., 2017; Pitney et al., 
2006; Rush, Adamack, Gordon, Lilly \& Janke, 2012; Saperstein et al., 2012); and increased selfconfidence and competence in skills (Mazerolle, Bowman, et al., 2015; Pitney et al., 2006; Woolnough \& Fielden, 2014). The benefits demonstrate the dynamic nature of mentoring relationships which results in mutual growth for both mentor and protégé (Cellini et al., 2017; Zanchetta et al., 2017).

\section{Formal Mentoring Programs}

Formal mentoring is defined by structured relationships (Vatan \& Temel, 2016), and has been studied predominantly in the form of formal programming within the practice of nursing (Bratt, 2009; Solowiej, Upton, \& Upton, 2010; Vatan \& Temel, 2016; Woolnough \& Fielden, 2004). Formal mentoring does occur in athletic training, typically via an assigned preceptor or supervisor within the student's clinical rotation (Mazerolle, Clines, et al., 2015; Mazerolle, Walker, et al., 2015; Nottingham et al., 2016; Walker et al., 2016). Outside of relationships created within a clinical rotation, only one formal mentoring program exists through the NATA, with the emphasis on pairing junior athletic training faculty members with mentors to help navigate through the challenges of working in higher education (National Athletic Trainers' Research and Education Foundation, 2018). Currently there are no formal mentoring programs through the NATA in place to assist newly certified athletic trainers in their transition to practice (Walker et al., 2016). While formal matched mentoring programs outside of clinical education have not been largely implemented within athletic training, the nursing field has created successful formal mentoring programs for their constituents that can be a template for programs within athletic training (Bratt, 2009; Solowiej, Upton, \& Upton, 2010; Woolnough \& Fielden, 2004). 
Within nursing, formal mentoring programs have high rates of efficacy for both protégés and mentors. Woolnough and Fielden (2014) report that those that engage in formal programs have a higher rate of self-confidence, self-esteem, and higher rates of promotion within their jobs. Vatan and Temel (2016) report positive changes in leadership for both mentors and protégés due to the implementation of a formal mentoring program. Bratt (2009) discusses the efficacy of the Wisconsin Nurse Retention Program (WNRP), which boasts a $90 \%$ retention rate for new graduate nurses at their hospitals or organizations of hire one year after completion of the program. The authors report that the program's efficacy may be due to the combination of educational and psychosocial support for newly licensed registered nurses, as well as tackling many of the issues that can lead to nursing attrition rates (Bratt, 2009). The importance of psychosocial support of mentoring relationships in athletic training has previously been reported by Walker et al. (2016) as a critical component in transition to practice by newly credentialed athletic trainers.

\section{Peer Mentoring \& Informal Mentoring}

Unlike the formal mentoring programs, informal mentoring relationships are unstructured in nature (Vatan \& Temel, 2016), develop into longer lasting relationships than structured pairings (Nottingham et al., 2016), and ensure better chemistry between the mentor-protégé pairing (Yamada et al., 2014). In athletic training, informal mentoring takes the form of peer mentoring (Mazerolle et al, 2014; Mazerolle, Walker et al., 2015; Nottingham et al., 2016; Walker et al., 2016), or between colleagues and supervisors (Nottingham et al., 2016;). Peer mentoring often develops around the socialization aspect of educational programs (Mazerolle et al., 2014) and transition to practice (Walker et al., 2016). Often, those that engage in peer mentoring relationships will reach out to their peers for advice or suggestions prior to contacting 
their supervisor (Mazerolle, Clines, et al., 2015; Walker et al., 2016). Informal mentoring relationships between colleagues assists with individual organization socialization (Mazerolle, Barrett, et al., 2016; Mazerolle, Walker, et al., 2015) and through the sharing of knowledge to be successful at the institution (Mazerolle, Barrett, et al., 2016).

Currently in athletic training, an informal mentoring program exists through the NATA's Ethnic Diversity Advisory Committee (EDAC) mentoring database. This database allows protégé's to search for mentors by state of employment, setting of employment and by ethnic background (NATA, n.d.c.), and the mentoring relationships are not officially assigned by either the NATA or the EDAC (NATA, n.d.d.). The EDAC provides general guidelines to facilitate the mentoring relationship, but leaves the intricacies of the relationship up to the discretion of the mentor and protégé (NATA, n.d.d.). These informal relationships are useful as learning and growth of the protégé can be facilitated in a more relaxed and comfortable manner (Mazerolle, Barrett, et al., 2016).

\section{Hybrid Mentoring Programs}

Yamada et al. (2014) developed a hybrid mentoring program which combined elements from both formal programming and informal mentoring relationships. Participants in the hybrid program could either self-select a specific mentor or complete a checklist of preferred attributes of their mentor (Yamada et al., 2014). The authors found that those that self-selected a specific mentor had a higher rate of satisfaction within the mandated mentoring program (Yamada et al., 2014). Nottingham et al. (2016) echoed similar results when looking at mentoring relationships that develop between preceptors. The authors discuss the implementation of a semi-structured approach to facilitating mentoring relationships between preceptors; this semi-structured approach would connect novice and experienced preceptors in a formal setting, allow for the 
relationships to develop organically, and allow participants to choose how and if they will continue the mentoring relationship (Nottingham et al., 2016).

\section{Mentoring Networks}

A mentor network allows a protégé to obtain and examine different perspectives, capitalize on each mentor's strengths, as well as aid in the ability of the protégé to develop crucial networking skills (Cellini et al., 2017; DeCastro et al., 2013). DeCastro et al. (2013) report that protégés benefitted from multiple mentors from varied backgrounds, areas of expertise and gender, as one person cannot solely fulfill all the protégé's needs. This argument is echoed by Wild, Canale, and Herdklotz (2017) in the case of developing a mentoring network for faculty, and by McBride, Campbell, Woods and Manson (2017) for nurses. Wild et al. (2017) discuss how the mentor groups collaborated with each other across various departments throughout campus to create a mutually beneficial learning environment in which people could share their skills and strengths with each other. McBride et al. (2017) state that mentoring networks can be especially beneficial if the initial mentor-protégé pairing is not successful. While the primary mentor-protégé pairing may not be as strong as initially predicted, the protégé's other mentors in the network proved to be more of an asset to the protégé than if they only had the single mentor pairing (McBride et al., 2017).

One application of mentoring network is through the concept of a speed mentoring network, in which participants meet with different potential mentors for short amounts of time to determine mutual interests, commonalities, and desire to pursue a mentoring relationship (Cellini et al., 2017; Kurré, Schweiger, Kulms, \& Guse, 2014; Serwint, Cellini, Spector, \& Gusic, 2014). Kurré et al. (2014) report mentors and protégés utilizing a ranking system for preferred choice of mentoring pairing after the initial meeting. The authors found that the speed mentoring pairings 
had greater longevity compared to the control group, and that the speed mentoring format allowed for more effective matching in the mentor-protégé relationship (Kurré et al., 2014). Cellini et al. (2017) found that over half of their participants expressed interest in pursuing a mentoring relationship because of the event, and protégés could connect with a broader network of potential mentors. Implementation of similar speed mentoring programs can be beneficial in health professions as protégés are exposed to a multitude of potential mentors, and initial compatibility of the mentoring relationship can be determined (Cellini et al., 2017).

\section{Mentoring in Athletic Training}

General Characteristics. Burnignham et al. (2010) note that the foundations of the profession of athletic training are based in mentoring relationships; therefore, it is imperative for mentors to understand what traits protégé's are looking for in the development of effective mentoring relationships. Burningham et al. (2010) identified key traits that are necessary for effective mentoring in athletic training: communication between the student and educator, development of the students' critical thinking skills, a high level of professionalism, and responsiveness to students. Similarly, Barrett et al. (2017), Nottingham et al. (2016) Mazerolle et al. (2017), and Pitney and Ehlers (2004) all report the necessity for strong interpersonal skills in effective mentoring relationships.

Gender. The June 2017 demographic information from the NATA indicates that female membership comprises $55 \%$ of the total membership (NATA, 2017). While mentoring relationships need to be examined within the entirety of athletic training, females within the profession are especially underserved in their mentoring needs (Eason et al., 2014). With over half of the membership population being comprised of women, it is crucial to have quality and competent mentors to serve this population, especially as related to work-life balance (Barrett et 
al., 2016) and the rigors of motherhood (Eason et al., 2014). Interestingly, when determining the most important characteristics for effective mentoring relationships, both Pitney et al. (2006) and Mazerolle et al. (2017) found that their participants ranked both gender and ethnicity as two of the lowest ranked criteria, suggesting that protégés value professional attributes of their mentors, rather than their demographic characteristics (Mazerolle et al., 2017).

As reported by Eason et al. (2014), Goodman et al. (2010), and Kahanov and Eberman (2011), female athletic trainers are changing their employment setting to establish work-life balance, or are leaving the profession of athletic training all together. Kahanov and Eberman (2011) report female athletic trainers begin to leave the profession of athletic training around the age of 28 in lieu of starting a family. This compares to the general decline of athletic trainers in the workforce after the age of 30, and male athletic trainers moving to the secondary school setting in their middle to late 40s (Kahanov \& Eberman, 2011). Goldman et al. (2010) discuss the barriers of gender equity in athletic training, as well as the traditional cultural stereotypes surrounding women's roles in society. Additional factors such as burnout, job satisfaction and work-family conflict may account for these changes in the workforce (Goldman et al., 2010; Kahanov \& Eberman, 2011).

Eason et al. (2014) explored issues related to work-life balance, motherhood, and the influence of mentors on National Collegiate Athletic Association (NCAA) Division I female athletic trainers. Two-thirds of the respondents in the study expressed the need for more female mentors to demonstrate the ability of managing the demands of high-level collegiate athletic training in conjunction with the rigors of motherhood and work-life balance (Eason et al., 2014). Moreover, the authors report that those respondents that had previous experiences observing female athletic trainers exhibiting work-life balance were more confident about their own 
abilities to remain in the profession (Eason et al., 2014). Unfortunately, while female respondents in the Eason study state the need for more female mentors, the authors note that females do not want to fill those roles themselves due to the time constraints associated with serving as a mentor or because they plan to leave the profession (Eason et al., 2014).

Ethnicity. Siple et al. (2015) address the concerns of mentoring African-American athletic training students, especially when combatting accounts of racism and sexism in the classroom and professional settings. The need to mentor African American students (particularly females), and the positive effects of mentoring on African American students were addressed. Respondents felt that same-ethnicity pairings would be beneficial, as mentors would have better insight on the challenges facing African American females in the profession (Siple et al., 2015). While same-gender and same-ethnicity pairings were preferred, respondents heavily favored interpersonal characteristics and perceived effectiveness of the mentoring relationship, regardless of the mentor’s gender or ethnicity (Siple et al., 2015).

\section{Mentoring in Nursing}

General Characteristics. Nursing research demonstrates commonalities with athletic training on reported qualities of effective mentors (Al-Hamdan et al., 2014; Block et al., 2005; Clark \& Casey 2016; Ferguson, 2011; Gray \& Smith, 2000; Yates, 2017; Zanchetta et al., 2017). Issues such as burnout, large workloads, lack of respect, and poor communication have all be cited as reasons for departure from the nursing profession (Block et al., 2005; Hayward, Bungay, Wolff \& MacDonald, 2016; McGilton, Boscart, Brown \& Bowers, 2014), which are comparable to the reasons given for the departure from athletic training (Barrett et al., 2016; Eason et al., 2014; Goodman et al., 2010; Kahanov \& Eberman, 2011; Mazerolle et al., 2012). However, the implementation of mentoring relationships has been found to positively affect retention rates 
(Block et al., 2005; Hensinger, Minerath, \& Robertson, 2005; Almada, Carafoli, Flattery, French, \& McNamara, 2004) through peer support, organizational socialization, and development of skills.

Gender. Woolnough and Fielden (2014) examined the impact of implementing a career development and mentoring program for female nurses working in the mental health sector. Nurses in the study that had access to the year-long formal mentorship program had significantly higher rates of promotion within their jobs, had an increase in self-confidence and self-esteem, reported a perceived increase in leadership effectiveness, and could highlight multiple examples of personal growth and development based on the techniques they had learned (Woolnough \& Fielden, 2014). Al-Hamdan et al. (2014) examined the perspectives of nursing students in Jordan, the United States, and the United Kingdom, and found that female Jordanian students preferred female mentors, and felt more comfortable with female mentors to ask questions, ask for help and support. While gender was a factor in their study, the authors note that protégés in other nursing research studies do not consider gender as an important characteristic in mentoring relationships (Al-Hamdan et al., 2014).

Recent trends in nursing literature have shifted to examine the mentoring needs of male students entering nursing educational programs (Abshire et al., 2017; Meadus \& Twomey, 2011; Rajacich, Kane, Williston, \& Cameron, 2013). Males are disproportionately represented within the field of nursing, and like females in athletic training, face the challenges of discrimination, as well as gender and sexual orientation stereotypes (Abshire et al., 2017; Meadus \& Twomey, 2011; Racjacich et al., 2013). These challenges may place male students at higher risk for poor academic performance and outcomes in their educational program (Abshire et al., 2017), as well as contribute to attrition rates of males in the nursing profession (Meadus \& Twomey, 2011; 
Racjacich et al., 2013). Peer mentoring and formal mentor support for male students in nursing education programs is shown to have a significant influence on graduation outcomes (Abshire et al., 2017); however, there is still a lack of formal mentoring programs available for male nurses (Meadus \& Twomey, 2011).

Ethnicity \& Cultural Influences. Al-Hamdan et al. (2014) examined the perceptions of student nurses and what qualities they perceived in effective mentors. The authors identified five key characteristics of effective mentors that were reported by students from Jordan, the United States, and the United Kingdom. While the groups of students reported similar characteristics for effective mentors, Jordanian students identified the need and desire for older mentors with more experience, as well as a preference for female mentors (Al-Hamdan et al., 2014). The authors attribute these characteristics to cultural influences of Jordanians, which values respect of elders and those individuals with more experience (Al-Hamdan et al., 2014).

Nursing research shows the need and desire for ethnically diverse nursing educators and mentors (Payton, Howe, Timmons \& Richardson, 2013). The authors state that some of the respondents in their study felt that mentors of a shared race could better understand their needs as a student and be able to relate to them on a different level than having a mentor of a different race, and having a diverse faculty could help increase diversity enrollment (Payton et al., 2013). Bannister, Bowen-Brady and Winfrey (2014) also echo the need for mentors of shared race and ethnic background, specifically to address potential cultural and linguistic challenges faced in clinical practice. While same-ethnicity mentoring pairings are not the most important attributes reported in mentoring relationships, there is value in shared cultural components that may not be addressed in cross-ethnic pairings (Bannister et al., 2014). 


\section{Mentoring in Business and Management}

Athletic training research can look to other professions outside of health professions to establish best practices in mentoring relationships, as well as strategies for the implementation of formal mentoring programs. While nursing is the most analogous in terms of similar characteristics of mentors (Al-Hamdan et al., 2014; Block et al., 2005; Clark \& Casey 2016; Ferguson, 2011; Gray \& Smith, 2000; Yates, 2017; Zanchetta et al., 2017) and factors affected retention (Block et al., 2005; Barrett et al., 2016; Eason et al., 2014; Goodman et al., 2010; Hayward et al., 2016; Kahanov \& Eberman, 2011; Mazerolle et al., 2012; McGilton et al., 2014), mentoring practices in business and management may be equally beneficial to implement in athletic training.

General Characteristics. Leck and Orser (2013) identify three broad categories of skills that mentors look for in potential protégés: ability, benevolence and integrity. Ability refers to the protégé’s capabilities and attributes that are necessary to assume the protégé role, and include characteristics such as accepting feedback and being open to suggestions, setting realistic goals, and being willing to learn from their mentor and follow their suggested advice (Leck \& Orser, 2013). Benevolence relates to the characteristics and chemistry created between mentor and protégé within the mentoring relationship, while integrity relates to the foundations of trust built within a mentoring relationship (Leck \& Orser, 2013).

Gender. Eliot et al. (2006) examined the importance of trust within mentoring relationships, especially cross-gender mentoring relationships. The authors found that female mentors, regardless of same or cross gender mentoring relationships, provided more psychosocial mentoring and support compared to their male counterparts, who provided more career mentoring support to their protégés (Eliot et al., 2006). The authors also state the need to 
ask the protégé what their expectations are for the mentoring relationship, as that may help guide whether a same or cross gender mentoring relationship will be more beneficial (Eliot et al., 2006).

Eliot et al. (2006) also found that both male and female mentors were less comfortable in cross-gender mentor relationships compared to same gender mentor relationships (Eliot et al., 2006). Zey (1991) reported similar findings; female protégés stated they felt more comfortable in same-gender mentoring pairings, as female mentors had a better understanding of their needs. Both authors attribute the lack of comfort to perceptions of competence and sexual connotations by those not engaged in the mentoring relationship (Eliot et al., 2006; Zey, 1991).

\section{Summary}

Strong interpersonal skills have been reported as essential traits in effective mentoring relationships throughout health professions and business literature (Al-Hamdan et al., 2014; Burnighman et al., 2010; Eliot et al., 2006; Ferguson, 2011; Gray \& Smith, 2000; Leck \& Orser, 2013; Mazerolle et al., 2017; Nottingham et al., 2016; Pitney \& Ehlers, 2004). Formal (Bratt, 2009; Mazerolle, Clines, et al., 2015; Mazerolle, Walker, et al., 2015; Nottingham et al., 2016; Solowiej, Upton, \& Upton, 2010; Vatan \& Temel, 2016; Walker et al., 2016; Woolnough \& Fielden, 2004) and informal (Mazerolle et al, 2014; Mazerolle, Walker et al., 2015; Nottingham et al., 2016; Vatan \& Temel, 2016; Walker et al., 2016; Yamada et al., 2014) mentoring programs have been successful in creating mentoring relationships, targeting specific populations, and targeting specific needs within a profession. The implementation of a hybrid mentoring program may be useful in expanding the protégé's network, and allow for relationships to develop organically rather than being forced (Nottingham et al., 2016; Yamada et al., 2014). 
Implementation of mentoring networks have also been determined to play a crucial role in meeting all the needs of the protégé by providing the protégé with varied perspectives (Cellini et al., 2017; DeCastro et al., 2013; McBride et al., 2017; Wild et al., 2017). Lastly, underserved populations, specifically women (Al-Hamdan et al., 2014; DeCastro et al., 2013; Eason et al., 2014; Eliot et al., 2006; Leck \& Orser, 2013; Shafer, 2009; Siple et al., 2015; Stamm \& Buddeberg-Fischer, 2011; Woolnough \& Fielden, 2014; Yamada, Slanetz, \& Boisele, 2014; Zey, 1991) and those that identify as ethnically diverse (Al-Hamdan et al., 2014; Siple et al., 2015), have been identified as groups that need quality mentors, especially to aid in retention within the profession. 


\section{Chapter III}

\section{Methodology}

\section{Introduction}

The implications of mentoring relationships from the student perspective in athletic training has been thoroughly examined (Barrett et al., 2016; Burnigham et al., 2010; Klossner, 2008; Mazerolle et al., 2017; Mazerolle et al., 2014; Mazerolle, Bowman, et al., 2015; Mazerolle, Dodge, et al., 2015; Mazerolle, Eason, et al., 2016; Mazerolle et al., 2012; Pitney \& Ehlers, 2004; Pitney et al., 2006). However, to date no original research has been done on mentoring relationships from the practicing clinician perspective. Furthermore, there is also an identified gap in the literature to examine the differences in perceptions on mentoring relationships based on gender (Mazerolle et al., 2017). These gaps in the research formed the underpinnings of the current study.

Pitney et al. (2006) created the survey tool Athletic Training Students Perceptions on Mentoring Effectiveness (ATSPME) to quantitatively examine the perceived importance of values and personal characteristics present in mentoring relationships. Mazerolle, Eason, et al. (2016) used the tool similarly to examine student athletic trainers’ perceptions of mentoring within clinical education. Mazerolle et al. (2017) continued with the tool to examine differences in rankings between athletic training students and preceptors. The ATSPME is a valid tool $(\alpha=.851)$ that examines the importance of personal values and characteristics present within mentoring relationships (Mazerolle et al., 2017; Mazerolle, Eason, et al., 2016; Pitney et al., 2006). Written permission was granted to utilize the ATSPME for this study, and approval was obtained from the Institutional Review Board prior to subject recruitment. 


\section{Review of the Purpose of Study}

The purpose of this quasi-experimental study was to examine the presence of mentoring relationships, as well as identify characteristics of effective mentors, within the District Six secondary school setting. Quantitative analysis was used to examine respondents’ mentors, as well as the values and personal characteristics deemed most significant in mentoring relationships.

\section{Specific Description of the Methodology}

Participants for the current study were recruited to participate via email distributed by the NATA. Limitations were set to only distribute the email to athletic trainers working in the secondary school setting within District Six of the NATA $(\mathrm{N}=1250)$. A follow up reminder email was sent out by the NATA two weeks after initial distribution. Follow up reminders were also posted on social media through the Southwestern Athletic Trainers' Association (SWATA) Young Professionals Committee Facebook and Twitter accounts.

Prior to the study, participants read the informed consent (Appendix A) at the beginning of the survey. Following acceptance of the informed consent, participants completed the online ATSPME. Respondents answered each question on the ATSPME utilizing a 5-point Likert scale, with answers ranging from “strongly agree (5)” to “strongly disagree (1)”. Upon completing the ATSPME, participants were asked to provide their demographic information, including gender, ethnicity, age, and state of employment. Demographics of the respondents can be found in Table 1.1-1.3. 


\section{Research Design of the Study}

The research design of this study was a quantitative, quasi-experimental design examining the perceived importance of identified values and roles in mentoring relationships. An electronic version of the survey was used to collect responses. Data analysis investigated gender differences in relation to the importance of interpersonal characteristics in mentoring relationships. The descriptive statistics revealed if athletic trainers identified having a mentor, the perceived effects of ethnicity, age, and gender on mentoring relationships, and the perceived effect mentoring relationships has on retention within the protégé’s profession.

\section{Sample, Population, and Source of Data}

The sample population consisted of athletic trainers within District Six that were employed within the secondary setting. Following IRB approval, participants were recruited via email distributed by the NATA to participate in the study. Participants read and acknowledged an informed consent prior to beginning the survey via Survey Monkey. A total of 1250 surveys were distributed, with 151 (12\% response rate) participants returning surveys. Of the 151 participants, 28 participants only answered the first two questions related to having a mentor, either currently or in the past. As such, these responses were only utilized in analysis for RQ2. In addition, demographic information was asked at the end of the survey, and as a result, not all respondents provided their information. Demographics of the participants can be found in Table 1.

\section{Inclusion Criteria}

Athletic trainers employed in the secondary school setting within District Six of the NATA were approached for inclusion in this study. Respondents were also NATA members that have opted in for research participation. 


\section{Exclusion Criteria}

Exclusion criteria for this study included individuals who were unable to read and understand the English language. The ATSPME was conducted online, so individuals without access to the online survey were also excluded.

\section{Instrumentation}

A copy of the survey used in this study can be found in Appendix B. Written permission was granted by the creator, Dr. William Pitney. The ATSPME survey is a valid tool $(\alpha=.851)$ to investigate the importance of identified mentoring attributes within the profession of athletic training (Mazerolle et al., 2017; Mazerolle, Eason, et al., 2016; Pitney et al., 2006). The reported Cronbach alpha for the current study can be found in Table 2.

The ATSPME can be divided into four sections (Mazerolle et al., 2017; Mazerolle, Eason, et al., 2016; Pitney et al., 2006). Section 1 asks the participants to identify if they currently had a mentor, if they ever had a mentor, and to identify the role of that mentor (e.g. head athletic trainer, program director); section 2 asked participants to utilize a 5-point Likert scale, ranging from “strongly agree (5)" to "strongly disagree (1)", to rate the significance of each identified mentoring attribute or value; section 3 asked participants to utilize a 5-point Likert scale, ranging from “strongly agree (5)” to “strongly disagree (1)”, to rate the significance of ethnicity, age, and gender in a mentoring relationship; section 4 obtained demographic information (Pitney et al., 2006).

Section 2 of the ATSPME can be divided into six subscales: educational, motivational, relationship/interpersonal, counseling, facilitative and career/employment (Mazerolle, Eason, et al., 2016). The Chronbach’s Alpha for each subscale can be found in Table 2. Values were 
subsequently derived from the sum of scores for each of the six subscales and analyzed for significant statistical differences.

\section{Dependent and Independent Variables}

The dependent variables in this study are identified as the six subscales of the ATSPME. The independent variable in this study is categorical values that allow for the comparison of groups, specifically the gender of the respondent.

\section{Informed Consent Process}

The informed consent process was displayed prior to the beginning of the online survey, as well as in the initial email distributed by the NATA. Anonymity was maintained using a unique identification code, using the first two initials of their first name, the first two initials of their last name, and the last two digits of their birth year. No incentives were available to participants except to contribute to research surrounding the availability and efficacy of mentoring relationships within the profession of athletic training.

\section{Statistical Analysis}

Statistical analysis was completed using IBM Statistical Package for Social Science (SPSS) software version 24. Anonymity was maintained using the personal identification code described above. Data was examined to determine the effects of gender (independent variable) on the importance of identified attributes and roles of effective mentoring utilizing a one-way ANOVA. Descriptive frequencies were examined to determine if respondents identified a mentor, as well as if effective mentoring has an impact on retention in the profession.

All data collected was ordinal in nature; utilization of a Likert scale was the most appropriate option for treatment of the data, with the respondent choices balanced around a neutral option to decrease the chances for an interval measurement (Bishop \& Herron, 2015). 
Subscale means (Appendix C) were analyzed using predetermined thematic codes provided by the creator of the ATSPME.

\section{Summary}

The purpose of this study was to examine the presence of mentoring relationships, as well as identify characteristics of effective mentors within the secondary school setting of District Six of the NATA. Data was collected anonymously and electronically utilizing the validated ATSPME survey. The intent of the data was to determine if secondary school athletic trainers identified as currently having a mentor, if they ever had a mentor, and to identify the role of that mentor. Identification of the most important attributes in a mentoring relationship, the perceived importance of shared demographic characteristics between mentor and protégé, as well as the perceived impact of mentoring relationship on retention were also examined. The results of the data may lead to future research in the establishment and development of effective mentoring relationships, as well as the identification of the most important attributes of an effective mentoring relationship. 


\section{Chapter IV}

\section{Analysis of Data}

\section{Introduction}

The purpose of this study was to examine the perceived importance of specific identified values and personal characteristics present in mentoring relationships in secondary school athletic trainers within District Six of the National Athletic Trainers' Association. Data was collected using the ATSPME, which has been established as a valid and reliable tool $(\alpha=.851)$ (Mazerolle et al., 2017; Mazerolle, Eason, et al., 2016; Pitney et al., 2006). Survey items were categorized into four separate sections: identification of a mentor (either current or past), perceived importance of identified mentoring roles and/or characteristics, perceived importance of shared demographic characteristics of mentor-protégé relationships, and respondent demographic information (Pitney et al., 2006). The findings from this study are relevant to other secondary school athletic trainers, and apply to athletic trainers engaged in mentoring relationships.

\section{Use of Statistical Analysis}

Quantitative data was collected for this study. A one-way ANOVA was utilized to examine differences between gender on the six subscales, as well as the individual questions, of the ATSPME. Identification of a mentor (either current or past), perceived impact of mentoring relationships on retention, and the perceived importance of shared gender, ethnicity and age of mentor and protégé were also examined using comparison of means.

Three assumptions for one-way ANOVA were examined prior to analysis: normally distributed population, equal variances, and independent observations (Aron, Coups, \& Aron, 2013). For the present study, respondents completed the survey individually and independently 
online. Normality checks and Levene's test were carried out, and the assumptions of one-way ANOVA were met.

\section{Results}

Gender Differences. The first research question explored if female athletic trainers in the secondary setting valued interpersonal characteristics of mentoring relationships more than male athletic trainers. It was hypothesized that significant statistical differences would exist between genders. A one-way ANOVA was performed on each of the subscales of the ATSPME, as well as the individual questions of the ATSPME. A significant statistical difference was revealed between genders in the relational subscale, $F(1)=4.525, \mathrm{p}=.035$. Significant statistical differences between gender existed in questions 2, 3, 23, 24, and 25 of the ATSPME. The ANOVA table for the subscale results can be found in Tables 3.1-3.2, and the ANOVA table for the individual question results can be found in Table 3.3-3.4.

Presence of a Mentor. The second research question explored if athletic trainers in the secondary setting identified as having a mentor, either currently or in the past. It was hypothesized that athletic trainers would identify as having a mentor. Answers to question 1 on the ATSPME (Appendix B) were analyzed. The frequency distribution table can be found in Table 4, and reported roles of current and past mentors can be found in Table 5.

Effects of Similar Gender, Age and Ethnicity. The third research question explored if similar gender, age, and ethnicity in the mentor-protégé relationship resulted in more positive perceptions of mentoring effectiveness. It was hypothesized that no differences would exist in the perception of mentoring effectiveness based on the similarity of gender, age, or ethnicity in the mentor-protégé relationship. The means and standard deviations are reported in Table 6.1, and the frequency distribution tables can be found in Tables 6.2-6.4. 
Effects on Retention. The final research question explored if effective mentoring could influence a protégé’s retention in their profession. It was hypothesized that the perception of effective mentoring would positively affect perceived retention within the protégé's profession. The means and standard deviations are reported in Table 7.1, and the frequency distribution tables can be found in Table 7.2.

\section{Summary}

The instrument used in this research study provided quantitative data sufficient to answer the four primary research questions. The research examined differences between the genders in the six stated subscales of the ATSPME, as well as in the individual questions of the tool. Additionally, the research sought to determine if athletic trainers in the secondary setting had a mentor, either currently or in the past. Demographic variable influences on effecting mentoring relationships were also examined. Lastly, the research examined if effective mentoring relationships had a perceived positive impact on retention in a protégé’s profession. One-way ANOVA was utilized to determine statistical significant differences between gender; and frequency tables were utilized to examine the identification of a mentor, as well as the importance of similar gender, age, and ethnicity in mentoring relationships, and the impact of mentoring relationships on retention in the protégé’s profession. 


\section{Chapter V}

\section{Discussion}

\section{Introduction}

As discussed, the characteristics of effective mentors have been documented throughout athletic training (Barrett et al., 2017; Bowman et al., 2013; Burningham et al., 2010; Mazerolle, Bowman, et al., 2015; Mazerolle, Walker, et al., 2015; Pitney \& Ehlers, 2004; Pitney et al., 2006) and nursing literature (Al-Hamdan et al., 2014; Block et al., 2005; Clark \& Casey 2016; Ferguson, 2011; Gray \& Smith, 2000; Yates, 2017; Zanchetta et al., 2017). Strong interpersonal skills, such as trust (Eliot, Leck, Orser \& Mossop, 2006; Ferguson, 2011; Leck \& Orser, 2013; Nottingham et al., 2016; Pitney \& Ehlers, 2004) and professionalism (Al-Hamdan et al., 2014; Burnighman et al., 2010; Gray \& Smith, 2000) are consistently reported as being highly valuable to protégés in health professions literature (Mazerolle et al., 2017; Pitney \& Ehlers, 2004).

Research has been done to investigate the student perspective of mentoring relationships in athletic training (Barrett et al., 2016; Burnigham et al., 2010; Klossner, 2008; Mazerolle et al., 2017; Mazerolle et al., 2014; Mazerolle, Bowman, et al., 2015; Mazerolle, Dodge, et al., 2015; Mazerolle, Eason, et al., 2016; Mazerolle et al., 2012; Pitney \& Ehlers, 2004; Pitney et al., 2006); however, no research has currently been done on perceptions of mentoring relationships from the practicing clinician perspective. Previous research has identified a gap in the literature identifying differences in perceptions on mentoring relationships based on gender (Mazerolle et al., 2017). The results of the current study aim to identify the presence of mentoring relationships as identified by secondary school athletic trainers. The results also aim to highlight the most important characteristics in effective mentoring relationships. By understanding the specific 
needs of protégés in the clinical setting, health professions like athletic training can focus on more targeted approaches to providing support throughout the protégé’s career.

\section{Summary of Results}

Gender Differences. A one-way ANOVA was conducted to compare differences between genders in the six subscales of the ATSPME (Appendix B). As predicted, significant statistical differences between genders was reported in the relational subscale $(F(1)=4.525, p=$ .035) (Table 3.1). The relational subscale included questions 3 and 13-15 on the ATSPME, which addressed the values of trust, the mentor's ability to provide helpful advice to the protégé, and the effectiveness of shared professional beliefs of mentor and protégé. While females had a lower mean compared to males, they reported a higher average minimum score; this indicates that female respondents in the study valued these characteristics more than their male counterparts (Table 3.2).

A one-way ANOVA was also conducted to compare differences between genders in the individual questions of the ATSPME. Significant statistical differences between gender were reported in questions 2, 3, 23, and 25 (Table 3.3). Question 2 stated that mentoring was more effective if the protégé received a lot of information. Significant statistical differences between genders were found $(F(1)=5.939, p=.016)$, with male respondents reporting a higher mean compared to female respondents (Table 3.4). Question 3 stated that mentoring was more effective if the mentor tutors the protégé. Significant statistical differences between genders were found $(\mathrm{F}(1)=11.177, \mathrm{p}=.001)$, with male respondents reporting a higher mean compared to female respondents (Table 3.4). Question 23 stated that mentoring is effective if the mentor is available to the protégé daily. Significant statistical differences were found between genders $(F(1)=8.048, p=.005)$, with male respondents reporting a higher mean compared female 
respondents (Table 3.4). Question 25 stated that mentoring is more effective when monitored by a faculty member or administrator. Significant statistical differences were found between genders $(\mathrm{F} 1)=4.770, \mathrm{p}=.031$ ), with male respondents reporting a higher mean and a higher maximum compared to female respondents (Table 3.4). The results from these four questions suggest that male respondents in the current study prefer more frequent interactions, as well as prefer more information to be provided by their mentors.

Presence of a Mentor. The researcher hypothesized that respondents in the current study would identify having a mentor. A frequency distribution table (Table 4) shows that most respondents, regardless of gender, reported not currently having a mentor, yet reported previously being mentored. In the original study by Pitney et al. (2006), the authors reported that 73\% of respondents identified as currently having a mentor; however, this study examined mentoring relationships from the perspective of athletic training students. The results of the current study reflect the lack of active mentoring that occurs in clinical practice.

The reported roles of mentors for this study are consistent with those found in the previous applications of this survey tool (Mazerolle et al., 2017; Mazerolle, Eason, et al., 2016; Pitney et al., 2006). Table 5 shows the distribution of reported roles of current and past mentors as reported in this study.

Effects of Similar Gender, Age and Ethnicity. Perceived importance of similar ethnicity, age, and gender of mentor and protégé were examined. The means and standard deviations are reported in Table 6.1. The means for all three questions were similar regardless of the respondent's gender. Interestingly, females reported lower maximum ranges for the importance of similar age and gender of the mentor and protégé (Table 6.1). 
As predicted, respondents in the study did not deem shared demographic characteristics of mentor and protégé as important for effective mentoring relationships (Tables 6.2-6.4). The results from this study are consistent with the results of the Pitney et al. (2006) and Mazerolle et al. (2017) studies, which also show that shared demographic characteristics of mentor and protégé are among the lowest rated items in the ATSPME.

Effects on Retention. Perceived effects of effective mentoring on the protégé's retention in their profession was examined. The means and standard deviations are reported in Table 7.1. The means were similar regardless of the respondent's gender. Interestingly, females reported higher maximum ranges for this question (Table 7.1).

As predicted, effective mentoring positively affects retention within the protégé's profession (Table 7.2). The results from the current study are consistent with previous literature (Almada et al., 2004; Block et al., 2005; Hensinger et al., 2005) which shows the implementation of mentoring relationships has positively impacted retention rates.

\section{Strengths and Limitations}

As reported by Fryrear (2015), external survey response rate is typically between 10$15 \%$. The response rate for this study was $12 \%$ of surveys distributed, and is lower than in the original Pitney et al. (2006) study of $24.56 \%$ and the Mazerolle et al. (2017) study of 30\%. While the response rate may be a limitation for the study, the results of the present study correlate with the findings of both the previous studies. Another limitation was the lack of representation of respondents from the State of Arkansas, as only three respondents identified as working in the state (Table 1.3). There was also a lack of ethnic diversity represented in the study, as most of the respondents identified as Caucasian/White (Table 1.2). Lastly, since the survey was distributed through the NATA, it may not have been not inclusive of all athletic trainers working 
in the state of Texas. Some athletic trainers practicing in the state are not members of the NATA, and therefore would not have received the study.

\section{Implications for Athletic Training}

Results of the current study show the lack of active mentoring relationships and the need for continued mentoring support for the practicing clinician. Previous research has shown that mentoring relationships are developed in educational practice (Burningham et al., 2010; Mazerolle et al., 2017; Mazerolle \& Dodge, 2015; Mazerolle, Eason, et al., 2016; Pitney \& Ehlers, 2004; Pitney et al., 2006), however no research has been done on how those relationships continue to develop once the student has graduated. Protégés in the clinical setting are more often seen as peers of their mentor, rather than the traditional hierarchical relationship seen in educational settings (Mazerolle, Clines, et al., 2015). Utilizing Kram’s (1983) model can be helpful in navigating the changes and evolution of the mentoring relationship within clinical practice.

The results of the current study indicate that effective mentoring positively affects retention within the protégé's profession; a finding similarly reported in nursing literature (Almada et al., 2004; Block et al., 2005; Hensinger et al., 2005). The development of targeted formal mentoring programs can be helpful in providing directed strategies to address the issues related to retention.

\section{Future Research}

As previously discussed, there is no current research on mentoring relationships from the practicing clinician perspective. Longitudinal studies should be conducted to examine how mentoring relationships adapt and change over time, especially as students transition to clinical practice. The current study should be expanded to the rest of the districts within the NATA to 
identify the needs of secondary school athletic trainers across the country. The current study could also be disseminated to other clinical settings within athletic training, to include college/universities, professional sports, and emerging settings (e.g. military, performing arts, public safety). The data obtained from this study can provide a clearer picture into the mentoring needs of practicing clinicians, and drive the development of formal programs to meet those needs.

The implementation of formal mentoring programming based on similar interests or career paths (Barrett et al., 2017; Cellini, Serwint, D’Alessandro, Schulte, \& Osman, 2017; Nottingham et al., 2017) has been an effective method for targeting specific needs and populations within a profession (Solowiej et al., 2010; Woolnough \& Fielden, 2014). Formal programs such as those found in nursing (Bratt, 2009, Solowiej et al., 2010; Woolnough \& Fielden, 2014) should be evaluated for utilization in athletic training. The NATA should continue to expand and support the Research and Education Foundation mentoring program to aid new athletic training faculty members. The NATA should also develop formal mentoring programs, with intentional focus on aiding the transition to practice for newly certified members, and addressing the needs of women in the profession.

Additionally, the research performed by Eason et al. (2014) should be expanded into other clinical settings of athletic training to create a clearer picture of the needs of women in the profession. Women that have been able to achieve high levels of work-life balance should be more vocal about their success, and serve as mentors to others in the profession. The newly created Women in Athletic Training LLC and Facebook group currently serves as a medium to connect female athletic trainers from all sectors of the profession. The group began in March 2018 and to date, has nearly 5000 active members. Topics ranging from treatment protocols, to 
managing work-life balance, and strategies for negotiations have all been discussed using peer and informal mentoring techniques. This group, in conjunction with the NATA, could develop formal mentoring programs specific to the needs of women in athletic training. Lastly, programs such as the one outlined in the Woolnough \& Fielden (2014) study should be examined to aid women in achieving leadership positions within their clinical setting.

Finally, the implementation of mentoring networks within the profession of athletic training should be explored in an effort for the protégé to capitalize on each mentor's strengths (Cellini et al., 2017; DeCastro et al., 2013). Innovative programs, such as a speed mentoring program (Cellini et al., 2017; Kurré et al., 2014; Serwint et al., 2014), should be examined for efficacy and possible implementation at the NATA National Convention. The convention provides an ideal setting to connect protégé's with a variety of potential mentors, and allows for discussion to continue throughout the week.

\section{Conclusions}

Mentoring relationships are an integral part of health professions, and are mutually beneficial to the mentor and protégé. The values of effective mentors, as well as similarity of protégé needs, have been thoroughly examined throughout health profession literature. Interpersonal skills such as trust and high levels of professionalism continue to be reported as the most important characteristics in a mentoring relationship. Active mentoring relationships need to be fostered and encouraged in clinical practice, with the focus on supporting protégés that are newly credentialed. More research should be conducted on identifying specific needs of protégés in clinical practice, with the intent of developing formal programming to aid in supporting those needs. Lastly, new and innovative programs should be implemented to foster the continued growth and development of the mentor and protégé. 


\section{References}

Abshire, D.A., Graves, J.M., Roberts, M.L., Katz, J., Barbosa-Leiker, C., \& Corbett, C.F. (2017). Student support in accelerated nursing programs: Gender-based perspectives and impact on academic outcomes. Nursing Outlook, 66(1), 84-93. doi: 0.1016/j.outlook.2017.08.010

Al-Hamdan, Z., Fowler, J., Bawardi, H., Norrie, P., Summers, L., \& Dowsett, D. (2014). Student nurses’ perceptions of a good mentor: A questionnaire survey of student nurses in the UK, USA, and Jordan. International Journal of Humanities and Social Science, 4(3), 248-256.

Almada, P., Carafoli, K., Flattery, J., French, F., \& McNamara, M. (2004). Improving the retention rate of newly graduated nurses. Journal for Nurses in Staff Development, 20(6), 268-273. doi: 10.1097/00124645-200411000-00006

Aron, A., Coups, E.J., \& Aron, E.N. (2013). Introduction to the analysis of variance. In J. Mosher (Ed.), Statistics for psychology (6 ${ }^{\text {th }}$ ed.) (pp. 317-376). Boston, MA: Pearson Education, Inc.

Balu, L. \& James, L. (2017). Facilitating protégé career development through skills of mentors. Journal of Education and Practice, 8(4), 39-44.

Bandura, A. (1977). Social learning theory. Upper Saddle River, NJ: Prentice Hall.

Banister, G., Bowen-Brady, H.M., \& Winfrey, M.E. (2014). Using career nurse mentors to support minority nursing students and facilitate their transition to practice. Journal of Professional Nursing, 30(4), 317-225. doi: 10.1016/j.profnurs.2013.11.001

Barrett, J.L., Mazerolle, S.M., \& Eason, C.M. (2016). Exploring senior level athletic training students’ perceptions on burnout and work-life balance. Athletic Training Education Journal, 11(2), 110-118. doi: 10.4085/1102110 
Barrett, J.L., Mazerolle, S.M., \& Nottingham, S.L. (2017). Attributes of effective mentoring relationships for novice faculty members: Perspectives of mentors and mentees. Athletic Training Education Journal, 12(2), 152-162. doi: 10.4085/1202152

Bishop, P.A., \& Herron, R.L. (2015). Use and misuse of the Likert item responses and other ordinal measures. International Journal of Exercise Science, 8(3), 297-302.

Black, R. (2017). E-mentoring the online doctoral student from the dissertation prospectus through dissertation completion. Journal of Learning in Higher Education, 13(1), 1-8.

Block, L.M., Claffey, C., Korrow, M.K. \& McCaffrey, R. (2005). The value of mentorship within nursing organizations. Nursing Forum, 40(4), 134-140.

Bowman, T.G., Mazerolle, S.M., \& Dodge, T.M. (2013). Mentoring and personal relationships are perceived benefits of serving as an athletic training preceptor. Athletic Training Education Journal, 8(3), 35-40. doi: 10.4085/080335

Bratt, M.M. (2009). Retaining the next generation of nurses: The Wisconsin nurse residency program provides a continuum of support. Journal of Continuing Education in Nursing, 40(9), 416-425. doi: 10.3928/00220124-20090824-05

Burningham, D.S., Deru, L., \& Berry, D.C. (2010). What traits make for an effective athletic training educator and mentor? Athletic Training Education Journal, 5(4), 183-186.

Cellini, M.M., Serwint, J.R., D’Alessandro, D.M., Schulte, E.E., \& Osman, C. (2017). Evaluation of a speed mentoring program: Achievement of short-term mentee goals and potential for longer-term relationships. Research in Pediatric Education, 17(5), 537-543. doi: 10.1016/j.acap.2016.12.012

Clark, L. \& Casey, D. (2016). Support for mentors: An exploration of the issues. British Journal of Nursing, 25(20), 1095-1100. doi: 10.12968/bjon.2016.25.20.1095 
Commission on Accreditation of Athletic Training Education. (n.d.) Search for Accredited Programs. Retrieved from http://caate.net/search-for-accredited-program/

Crisp, G. \& Cruz, I. (2009). Mentoring college students: A critical review of literature between 1990 and 2007. Research in Higher Education, 50(6), 525-545. doi: 10.1007/s11162009-9130-2

DeCastro, R., Sambuco, D., Ubel, P.A., Stewart, A., \& Jagsi, R. (2013). Mentor networks in academic medicine: Moving beyond dyadic conception of mentoring for junior faculty researchers. Academic Medicine, 88(4), 488-496. doi: 10.1097/ACM.0b013e318285d302

Eason, C.M., Mazerolle, S.M., \& Goodman, A. (2014). Motherhood and work-life balance in the National Collegiate Athletic Association Division I setting: Mentors and the female athletic trainer. Journal of Athletic Training, 49(4), 532-539. doi: 10.4085/1062-605049.3.03

Elliott, C., Leek, J.D., Orser, B., Mossop, C. (2006). An exploration of gender and trust in mentoring relationships. Journal of Diversity Management, 1(1), 1-11. doi: 10.19030/jdm.v1i1.5024

Ferguson, L.M. (2011). From the perspective of new nurses: What do effective mentors look like in practice?. Nurse Education in Practice, 11(2), 119-123. doi: 10.1016/j.nepr.2010.11.003

Fryrear, A. (2015). What's a good survey response rate? Retrieved from ttps://www.surveygizmo.com/resources/blog/survey-response-rates/

Goodman, A., Mensch, J.M., Jay, M., French, K.E., Mitchell, M.F., \& Fritz, S.L. (2010). Retention and attrition in the National Collegiate Athletic Association Division I football bowl subdivision setting. Journal of Athletic Training, 45(3), 287-298. 
Gotian, R. (2016). Mentoring the mentors: Just because you have the title doesn’t mean you know what you are doing. College Student Journal, 50(1), 1-4.

Gray, M.A., \& Smith, L.N. (2000). The qualities of an effective mentor from the student nurse's perspective: Findings from a longitudinal qualitative study. Journal of Advanced Nursing, 32(6), 1542-1549.

Hayward, D., Bungay, V., Wolff, A.C., \& MacDonald, V. (2016). A qualitative study of experienced nurses’ voluntary turnover: Learning from their perspectives. Journal of Clinical Nursing, 25(9/10), 1336-1345. doi: 10.1111/jocn.13210

Hensinger, B., Minerath, S., \& Robertson, K. (2005). Asset protection: Maintaining and retaining your workforce. Journal of Nursing Administration, 35(6), 268-272.

Jakubik, L.D. (2008). Mentoring beyond the first year: Predictors of mentoring benefits for pediatric staff nurse protégés. Journal of Pediatric Nursing, 23(4), 269-281. doi: 10.1016/j.pedn.2007.05.001

Kahanov, L. \& Eberman, L.E. (2011). Age, sex, and setting factors and labor force in athletic training. Journal of Athletic Training, 46(4), 424-430. doi: 10.4085/1062-6050-46.4.424

Kram, K. (1983). Phases of the mentor relationship. Academy of Management Journal, 26(4), 608-625. doi: 10.2307/255910

Kurré, J., Schweigert, E., Kulms, G., \& Guse, A.H. (2014). Speed mentoring: Establishing successful relationships. Medical Education, 48(11), 1131. doi: 10.1111/medu.12555

Leck, J. \& Orser, B. (2013). Fostering trust in mentoring relationships: an exploratory study. Equality, Diversity and Inclusion: An International Journal, 32(4), 410-425. doi: 10.1108/EDI-01-2010-0007

Mazerolle, S.M., Barrett, J.L., \& Nottingham, S. (2016). Examining the factors that facilitate 
athletic training faculty socialization into higher education. Athletic Training Education Journal, 11(4), 208-218. doi: 10.4085/1104208

Mazerolle, S.M., Barrett, J.L., Eason, C.M., \& Nottingham, S.L. (2017). Comparing preceptor and student perceptions on mentoring characteristics: An exploratory study. International Journal of Athletic Therapy \& Training, 22(2), 70-77. doi: 10.1123/ijatt.2015-0066

Mazerolle, S.M., Bowman, T.G., \& Dodge, T.M. (2014). Athletic training student socialization part I: Socializing students in undergraduate athletic training programs. Athletic Training Education Journal, 9(2), 72-79. doi: 10.4085/090272

Mazerolle, S.M., Clines, S., Eason, C.M. \& Pitney, W.A. (2015). Perceptions of support networks during the graduate-assistant athletic trainer experience. Journal of Athletic Training, 50(12), 1256-1266. doi: 10.4085/1062-6050-50.11.09

Mazerolle, S.M. \& Dodge, T. (2015). Role of clinical education experiences on athletic training students’ development of professional commitment. Athletic Training Education Journal, 10(2), 138-145. doi: 10.4085/1002138

Mazerolle, S.M., Eason, C.M., Nottingham, S., \& Barrett, J.L. (2016). Athletic training students’ perceptions of mentorship in clinical education. Athletic Training Education Journal, 11(2), 72-81. doi: 10.4085/110272

Mazerolle, S.M., Gavin, K.E., Pitney, W.A. Casa, D.J. \& Burton, L. (2012). Undergraduate athletic training students’ influences on career decisions after graduation. Journal of Athletic Training, 47(6), 679-693. doi: 10.4085/1062-6050-47.5.16

Mazerolle, S.M., Walker, S.E., \& Thrasher, A.B. (2015). Exploring the transition to practice for the newly credentialed athletic trainer: A programmatic view. Journal of Athletic Training, 50(10), 1042-1053. doi: 10.4085/1062-6050.50.9.02 
McBride, A.B., Campbell, J., Woods, N.F., \& Manson, S.M. (2017). Building a mentoring network. Nursing Outlook, 65(3), 305-314. doi: 10.1016/j.outlook.2016.12.001

McCullough, B., Marton, G.E., \& Ramnanan, C.J. (2015). How can clinician-educator training programs be optimized to match clinician motivations and concerns?. Advances in

Medical Education and Practice, 6, 45-54. doi: 10.2147/AMEP.S70139

McGilton, K.S., Boscart, V.M., Brown, M., \& Bowers, B. (2014). Making tradeoffs between reasons to leave and reasons to stay employed in long-term care homes: Perspectives of licensed nursing staff. International Journal of Nursing Studies, 51(6), 917-926. doi: 10.1016/j.ijnurstu.2013.10.015

Mentor [Def. 1 \& 2]. (n.d.). In Dictionary.com, Retrieved from http://www.dictionary.com/browse/mentor?s=t.

Meadus, R.J., \& Twomey, J.C. (2011). Men student nurses: The nursing education experience. Nursing Forum, 46(4), 269-279. doi: 10.1111/j.1744-6198.2011.00239.x

Mitchell, M.E., Eby, L.T., \& Ragins, B.R. (2015). My mentor, my self: Antecedents outcomes of perceived similarity in mentoring relationships. Journal of Vocational Behavior, 89, 1-9. doi: 10.1016/j.jvb.2015.04.008

National Athletic Trainers’ Association. (n.d.a.). About. Retrieved from http://www.nata.org/about

National Athletic Trainers’ Association. (n.d.b.). Athletic Training Glossary. Retrieved from https://www.nata.org/about/athletic-training/athletic-training-glossary

National Athletic Trainers’ Association. (n.d.c.). EDAC-Mentoring. Retrieved from https://www.nata.org/edac/mentors 
National Athletic Trainers’ Association. (n.d.d.). EDAC Mentoring FAQ. Retrieved from https://www.nata.org/professional-interests/diversity/resources/mentoring-FAQ

National Athletic Trainers’ Association. (2017). Resources. Retrieved from https://www.nata.org/sites/default/files/ethnicity-report.pdf

National Athletic Trainers’ Research and Education Foundation. (2018). Faculty Mentor Program Overview. Retrieved from http://natafoundation.org/request-funding/facultymentor-program-overview/

Nottingham, S., Barrett, J.L., Mazerolle, S.M., \& Eason, C.M. (2016). Examining the role mentorship plays in the development of athletic training preceptors. Athletic Training Education Journal, 11(3), 127-137. doi: 10.4085/1103127

Nottingham, S.L., Mazerolle, S.M., \& Barrett, J.L. (2017). Promising and established investigators’ experiences participating in the National Athletic Trainers’ Association Foundation Research Mentor Program. Journal of Athletic Training, 52(4), 368-376. doi: 10.4085/1062-6050-52.2.11

Payton, T.D., Howe, L.A., Timmons, S.M., \& Richardson, M.E. (2013). African American nursing students’ perceptions about mentoring. Nursing Education Research, 34(3), 173177. doi: 10.1097/00024776-201305000-00008

Pitney, W.A., \& Ehlers, G.G. (2004). A grounded theory study of the mentoring process involved with undergraduate athletic training students. Journal of Athletic Training, 39(4), 344-351.

Pitney, W.A., Ehlers, G., \& Walker, S. (2006). A descriptive study of athletic training students’ perceptions on effective mentoring roles. The Internet Journal of Allied Health Sciences and Practices, 4(2), 1-8. 
Pogrund, R.L. \& Cowan, C. (2013). Perceptions of a statewide mentor program for new itinerant vision professionals. Journal of Visual Impairment \& Blindness, 107(5), 351-362.

Rajacich, D., Kane, D., Williston, C., \& Cameron, S. (2013). If they do call you a nurse, it is always a "male nurse": Experiences of men in the nursing profession. Nursing Forum, 48(1), 71-80. doi: 10.1111/nuf.12008

Rush, K.L., Adamack, M., Gordon, J., Lilly, M., \& Janke, R. (2012). Best practices of formal new graduate nurse transition programs: An integrative review. International Journal of Nursing Studies, 50(3), 345-356. doi: 10.1016/j.ijnurstu.2012.06.009

Saperstein, A.K., Viera, A.J., \& Firnhaber, G.C. (2012). Mentorship and job satisfaction among Navy family physicians. Military Medicine, 177(8), 883-888. doi: 10.7205/MILMED-D11-00362

Schafer, A.I. (2009). The vanishing physician-scientist. Ithica, NY: Cornell University Press.

Schrodt, P., Cawyer, C.S. \& Sanders, R. (2003). An examination of academic mentoring behaviors and new faculty members' satisfaction with socialization and tenure and promotion processes. Communication Education, 52(1), 17-29. doi:

$10.1080 / 03634520302461$

Serwint, J.R., Cellini, M.M., Spector, N.D., \& Gusic, M.E. (2014). The value of speed mentoring in a pediatric academic organization. Academic Pediatrics, 14(4), 335-340. doi: 10.1016/j.acap.2014.02.009

Shea, G.F. (1992). Mentoring: A practical guide. Menlo Park, CA: Crisp Publications, Inc. Siple, B.J., Hopson, R.K., Sobehart, H.C., \& Turocy, P.S. (2015). Who should mentor me? Giving a voice to black women athletic training students. Athletic Training Education Journal, 10(2), 146-158. doi: 10.4085/1002146 
Solowiej, K., Upton, P. \& Upton, D. (2010). Supporting the transition from student to practitioner: A scheme to support the development of newly qualified practitioners. International Journal of Therapy and Rehabilitation, 17(9), 494-504.

Stamm, M. \& Buddeberg-Fischer, B. (2011). The impact of mentoring during postgraduate training on doctors' career success. Medical Education, 45(5), 488-496. doi: 10.1111/j.1365-2923.2010.03857.x

Vatan, F. \& Temel, A.B. (2016). A leadership development program through mentorship for clinical nurses in Turkey. Nursing Economics, 34(5), 242-250.

Walker, S.E., Thrasher, A.B., \& Mazerolle, S.M. (2016). Exploring the perceptions of newly credentialed athletic trainers as they transition to practice. Journal of Athletic Training, 51(8), 601-612. doi: 10.4085/1062-6050-51.9.12

Wild, L., Canale, A.M., \& Herdklotz, C. (2017). The power of many: Mentoring networks for growth and development. College and University, 92(2), 37-41.

Woolnough, H.M. \& Fielden, S.L. (2014). The impact of a career development and mentoring programme on female mental health nurses: A longitudinal, qualitative study. Gender in Management: An International Journal, 29(2), 108-122. doi: 10.1108/GM-05-2013-0049

Yamada, K., Slanetz, P.J., \& Boiselle, P.M. (2014). Perceived benefits of a radiology resident mentoring program: Comparison of residents with self-selected vs assigned mentors. Canadian Association of Radiologists Journal, 65(2), 186-191. doi: 10.1016/j.carj.2013.04.001

Yates, J. (2017). Mentoring in radiologic technology. Radiologic Technology, 88(3), 349-353. Yoon, L., Campbell, T., Bellemore, W., Ghawi, N., Lai, P., Desveaux, L., ... Brooks, D. (2017). Exploring mentorship from the perspective of physiotherapy mentors in Canada. 
Physiotherapy Canada, 69(1), 38-46. doi: 10.3138/ptc.2015-52

Zanchetta, M.S., Bailey, A., Kolisnyk, O., Baku, L., Schwind, J., Osino, E., ... Yu, L. (2017). Mentors' and mentees; intellectual-partnership through the lens of the Transformative Learning Theory. Nurse Education in Practice, 25, 111-120.

doi:10.1016/j.nepr.2017.05.009

Zey, M. (1991). The mentor connection: Strategic alliances in corporate life. New Brunswick, NJ: Transaction Publishers. 
Table 1.1

Demographics: Age and Gender of Respondents

\begin{tabular}{ccccc}
\hline Gender & N & Min & Max & Mean \\
\hline Male & 54 & 25 & 65 & 43.43 \\
Female & 65 & 33 & 55 & 34.55 \\
\hline
\end{tabular}


Table 1.2

Demographics: Ethnicity

\begin{tabular}{cc}
\hline Ethnicity & $\mathrm{N}$ \\
\hline African American & 5 \\
Asian American & 2 \\
Caucasian/White & 100 \\
Hispanic/Latino & 13 \\
Other & 1 \\
\hline
\end{tabular}


Table 1.3

Demographics: State of Employment

\begin{tabular}{cc}
\hline State & $\mathrm{N}$ \\
\hline Arkansas & 3 \\
Texas & 119 \\
\hline
\end{tabular}


Table 2

Cronbach's Alpha for ATSPME Subscales

\begin{tabular}{cc}
\hline & Cronbach's Alpha \\
\hline Educational & .853 \\
Motivational & .869 \\
Relational & .866 \\
Counseling & .862 \\
Facilitative & .882 \\
Career & .887 \\
\hline
\end{tabular}


Table 3.1

ANOVA Table for ATSPME Subscales Based on Respondent Gender

\begin{tabular}{clccccc}
\hline & & SS & df & MS & F & Sig. \\
\hline \multirow{2}{*}{ Educational } & Between Groups & .098 & 1 & .098 & .420 & .518 \\
& Within Groups & 27.707 & 119 & .233 & & \\
\hline \multirow{2}{*}{ Motivational } & Between Groups & .001 & 1 & .001 & .002 & .965 \\
& Within Groups & 36.385 & 118 & .308 & & \\
\hline \multirow{2}{*}{ Relational } & Between Groups & 1.274 & 1 & 1.274 & 4.525 & $.035^{*}$ \\
& Within Groups & 33.503 & 119 & .282 & & \\
\hline \multirow{2}{*}{ Counseling } & Between Groups & .129 & 1 & .129 & .326 & .569 \\
& Within Groups & 46.530 & 118 & .394 & & \\
\hline Facilitative & Between Groups & .968 & 1 & .968 & 2.698 & .103 \\
& Within Groups & 43.055 & 120 & .359 & & \\
\hline \multirow{2}{*}{ Career } & Between Groups & .193 & 1 & .193 & .526 & .470 \\
& Within Groups & 43.773 & 119 & .368 & & \\
\hline
\end{tabular}

$* \mathrm{p}<.05$ 
Table 3.2

Descriptive Statistics for ATSPME Subscales Based on Respondent Gender

\begin{tabular}{|c|c|c|c|}
\hline Subscale & & Male & Female \\
\hline \multirow[t]{4}{*}{ Educational } & $\mathrm{N}$ & 55 & 66 \\
\hline & Mean & 4.1606 & 4.1035 \\
\hline & SD & .61360 & .33686 \\
\hline & Range & $1.00-5.00$ & $3.33-4.83$ \\
\hline \multirow[t]{4}{*}{ Motivational } & $\mathrm{N}$ & 54 & 66 \\
\hline & Mean & 4.2531 & 4.2576 \\
\hline & $\mathrm{SD}$ & .64080 & .47428 \\
\hline & Range & $1.00-5.00$ & $3.00-5.00$ \\
\hline \multirow[t]{4}{*}{ Relational } & $\mathrm{N}$ & 55 & 66 \\
\hline & Mean & 4.2818 & 4.0758 \\
\hline & $\mathrm{SD}$ & .64917 & .40660 \\
\hline & Range & $1.00-5.00$ & $3.25-5.00$ \\
\hline \multirow[t]{4}{*}{ Counseling } & $\mathrm{N}$ & 55 & 65 \\
\hline & Mean & 4.2788 & 4.3077 \\
\hline & SD & .64395 & .46138 \\
\hline & Range & $1.00-5.00$ & $3.33-5.00$ \\
\hline \multirow[t]{4}{*}{ Facilitative } & $\mathrm{N}$ & 56 & 66 \\
\hline & Mean & 3.9464 & 3.7677 \\
\hline & SD & .72691 & .46398 \\
\hline & Range & $1.33-5.00$ & $3.00-5.00$ \\
\hline \multirow[t]{4}{*}{ Career } & $\mathrm{N}$ & 55 & 66 \\
\hline & Mean & 3.9727 & 4.0530 \\
\hline & SD & .68325 & .53442 \\
\hline & Range & $1.00-5.00$ & $1.00-5.00$ \\
\hline
\end{tabular}


Table 3.3

ANOVA Table for Individual Questions Based on Respondent Gender

\begin{tabular}{|c|c|c|c|c|c|c|}
\hline & & SS & $\mathrm{df}$ & MS & $\mathrm{F}$ & Sig. \\
\hline \multirow[t]{2}{*}{ Q2 } & Between Groups & 4.054 & 1 & 4.054 & 5.939 & $.016^{*}$ \\
\hline & Within Groups & 81.913 & 120 & .683 & & \\
\hline \multirow[t]{2}{*}{ Q3 } & Between Groups & 6.901 & 1 & 6.901 & 11.177 & $.001 *$ \\
\hline & Within Groups & 74.091 & 120 & .617 & & \\
\hline \multirow[t]{2}{*}{ Q4 } & Between Groups & .028 & 1 & .028 & .066 & .797 \\
\hline & Within Groups & 50.439 & 120 & .420 & & \\
\hline \multirow[t]{2}{*}{ Q5 } & Between Groups & .017 & 1 & .017 & .047 & .828 \\
\hline & Within Groups & 43.524 & 120 & .363 & & \\
\hline \multirow[t]{2}{*}{ Q6 } & Between Groups & .671 & 1 & .671 & 1.655 & .201 \\
\hline & Within Groups & 48.649 & 120 & .405 & & \\
\hline \multirow[t]{2}{*}{ Q7 } & Between Groups & .077 & 1 & .077 & .150 & .699 \\
\hline & Within Groups & 61.300 & 120 & .511 & & \\
\hline \multirow[t]{2}{*}{ Q8 } & Between Groups & .134 & 1 & .134 & .382 & .538 \\
\hline & Within Groups & 41.767 & 119 & .351 & & \\
\hline \multirow[t]{2}{*}{ Q9 } & Between Groups & .228 & 1 & .228 & .412 & .522 \\
\hline & Within Groups & 65.239 & 118 & .553 & & \\
\hline \multirow[t]{2}{*}{ Q10 } & Between Groups & .005 & 1 & .005 & .006 & .936 \\
\hline & Within Groups & 86.922 & 120 & .724 & & \\
\hline \multirow[t]{2}{*}{ Q11 } & Between Groups & .227 & 1 & .227 & .289 & .592 \\
\hline & Within Groups & 94.199 & 120 & .785 & & \\
\hline \multirow[t]{2}{*}{ Q12 } & Between Groups & .007 & 1 & .007 & .019 & .892 \\
\hline & Within Groups & 44.076 & 119 & .370 & & \\
\hline \multirow[t]{2}{*}{ Q13 } & Between Groups & .208 & 1 & .208 & .383 & .537 \\
\hline & Within Groups & 65.112 & 120 & .543 & & \\
\hline \multirow[t]{2}{*}{ Q14 } & Between Groups & 1.419 & 1 & 1.419 & 1.318 & .253 \\
\hline & Within Groups & 129.245 & 120 & 1.077 & & \\
\hline \multirow[t]{2}{*}{ Q15 } & Between Groups & .010 & 1 & .010 & .024 & .878 \\
\hline & Within Groups & 50.073 & 119 & .421 & & \\
\hline \multirow{2}{*}{ Q16 } & Between Groups & .324 & 1 & .324 & .892 & .347 \\
\hline & Within Groups & 43.512 & 120 & .363 & & \\
\hline \multirow[t]{2}{*}{ Q17 } & Between Groups & 1.312 & 1 & 1.312 & 1.535 & .218 \\
\hline & Within Groups & 101.664 & 119 & .854 & & \\
\hline \multirow[t]{2}{*}{ Q18 } & Between Groups & .247 & 1 & .247 & .515 & .474 \\
\hline & Within Groups & 57.597 & 120 & .480 & & \\
\hline \multirow[t]{2}{*}{ Q19 } & Between Groups & .661 & 1 & .661 & .745 & .390 \\
\hline & Within Groups & 105.603 & 119 & .887 & & \\
\hline \multirow[t]{2}{*}{ Q20 } & Between Groups & .089 & 1 & .089 & .101 & .751 \\
\hline & Within Groups & 105.382 & 119 & .886 & & \\
\hline \multirow{2}{*}{ Q21 } & Between Groups & .287 & 1 & .287 & .625 & .431 \\
\hline & Within Groups & 55.221 & 120 & .460 & & \\
\hline \multirow[t]{2}{*}{ Q22 } & Between Groups & .082 & 1 & .082 & .129 & .721 \\
\hline & Within Groups & 76.312 & 120 & .636 & & \\
\hline
\end{tabular}




\begin{tabular}{|c|c|c|c|c|c|c|}
\hline & & SS & $\mathrm{df}$ & MS & $\mathrm{F}$ & Sig. \\
\hline Q23 & $\begin{array}{c}\text { Between Groups } \\
\text { Within Groups }\end{array}$ & $\begin{array}{c}10.005 \\
149.175\end{array}$ & $\begin{array}{c}1 \\
120\end{array}$ & $\begin{array}{c}10.005 \\
1.243\end{array}$ & 8.048 & $.005^{*}$ \\
\hline Q24 & $\begin{array}{l}\text { Between Groups } \\
\text { Within Groups }\end{array}$ & $\begin{array}{c}3.532 \\
116.370\end{array}$ & $\begin{array}{c}1 \\
120\end{array}$ & $\begin{array}{c}3.532 \\
.970\end{array}$ & 3.642 & .059 \\
\hline Q25 & $\begin{array}{l}\text { Between Groups } \\
\text { Within Groups }\end{array}$ & $\begin{array}{c}4.522 \\
113.773\end{array}$ & $\begin{array}{c}1 \\
120\end{array}$ & $\begin{array}{c}4.522 \\
.948\end{array}$ & 4.770 & $.031^{*}$ \\
\hline Q26 & $\begin{array}{c}\text { Between Groups } \\
\text { Within Groups }\end{array}$ & $\begin{array}{c}2.772 \\
141.597\end{array}$ & $\begin{array}{c}1 \\
120\end{array}$ & $\begin{array}{l}2.772 \\
1.180\end{array}$ & 2.349 & .128 \\
\hline Q27 & $\begin{array}{l}\text { Between Groups } \\
\text { Within Groups }\end{array}$ & $\begin{array}{c}.307 \\
83.701\end{array}$ & $\begin{array}{c}1 \\
120\end{array}$ & $\begin{array}{l}.307 \\
.698\end{array}$ & .440 & .508 \\
\hline Q28 & $\begin{array}{c}\text { Between Groups } \\
\text { Within Groups }\end{array}$ & $\begin{array}{c}.013 \\
52.913\end{array}$ & $\begin{array}{c}1 \\
120\end{array}$ & $\begin{array}{l}.013 \\
.441\end{array}$ & .029 & .865 \\
\hline Q29 & $\begin{array}{l}\text { Between Groups } \\
\text { Within Groups }\end{array}$ & $\begin{array}{c}.039 \\
91.929\end{array}$ & $\begin{array}{c}1 \\
120\end{array}$ & $\begin{array}{l}.039 \\
.766\end{array}$ & .050 & .823 \\
\hline Q30 & $\begin{array}{c}\text { Between Groups } \\
\text { Within Groups }\end{array}$ & $\begin{array}{c}.012 \\
69.012\end{array}$ & $\begin{array}{c}1 \\
120\end{array}$ & $\begin{array}{l}.012 \\
.575\end{array}$ & .021 & .885 \\
\hline
\end{tabular}

$* \mathrm{p}<.05$ 
Table 3.4

Descriptive Statistics for ATSPME Individual Questions Based on Respondent Gender

\begin{tabular}{|c|c|c|c|}
\hline & & Male & Female \\
\hline \multirow[t]{4}{*}{$\mathrm{Q} 2$} & $\mathrm{~N}$ & 56 & 66 \\
\hline & Mean & 4.21 & 3.85 \\
\hline & SD & .847 & .808 \\
\hline & Range & $1.00-5.00$ & $2.00-5.00$ \\
\hline \multirow[t]{4}{*}{ Q3 } & $\mathrm{N}$ & 56 & 66 \\
\hline & Mean & 4.25 & 3.77 \\
\hline & $\mathrm{SD}$ & .769 & .800 \\
\hline & Range & $1.00-5.00$ & $1.00-5.00$ \\
\hline \multirow[t]{4}{*}{ Q4 } & $\mathrm{N}$ & 56 & 66 \\
\hline & Mean & 4.25 & 4.53 \\
\hline & SD & .763 & .533 \\
\hline & Range & $1.00-5.00$ & $3.00-5.00$ \\
\hline \multirow[t]{4}{*}{ Q5 } & $\mathrm{N}$ & 56 & 66 \\
\hline & Mean & 4.64 & 4.67 \\
\hline & SD & 699 & .506 \\
\hline & Range & $1.00-5.00$ & $3.00-5.00$ \\
\hline \multirow[t]{4}{*}{ Q6 } & $\mathrm{N}$ & 56 & 66 \\
\hline & Mean & 4.52 & 4.67 \\
\hline & SD & .786 & .475 \\
\hline & Range & $1.00-5.00$ & $4.00-5.00$ \\
\hline \multirow[t]{4}{*}{ Q7 } & $\mathrm{N}$ & 56 & 66 \\
\hline & Mean & 4.27 & 4.32 \\
\hline & SD & .798 & .636 \\
\hline & Range & $1.00-5.00$ & $2.00-5.00$ \\
\hline \multirow[t]{4}{*}{ Q8 } & $\mathrm{N}$ & 56 & 65 \\
\hline & Mean & 4.52 & 4.58 \\
\hline & SD & .687 & .497 \\
\hline & Range & $1.00-5.00$ & $4.00-5.00$ \\
\hline \multirow[t]{4}{*}{ Q9 } & $\mathrm{N}$ & 54 & 66 \\
\hline & Mean & 4.19 & 4.27 \\
\hline & SD & .803 & .692 \\
\hline & Range & $1.00-5.00$ & $2.00-5.00$ \\
\hline \multirow[t]{4}{*}{ Q10 } & $\mathrm{N}$ & 56 & 66 \\
\hline & Mean & 3.98 & 3.97 \\
\hline & SD & .842 & .859 \\
\hline & Range & $1.00-5.00$ & $2.00-5.00$ \\
\hline \multirow[t]{4}{*}{ Q11 } & $\mathrm{N}$ & 56 & 66 \\
\hline & Mean & 3.57 & 3.48 \\
\hline & $\mathrm{SD}$ & .871 & .899 \\
\hline & Range & $1.00-5.00$ & $2.00-5.00$ \\
\hline
\end{tabular}




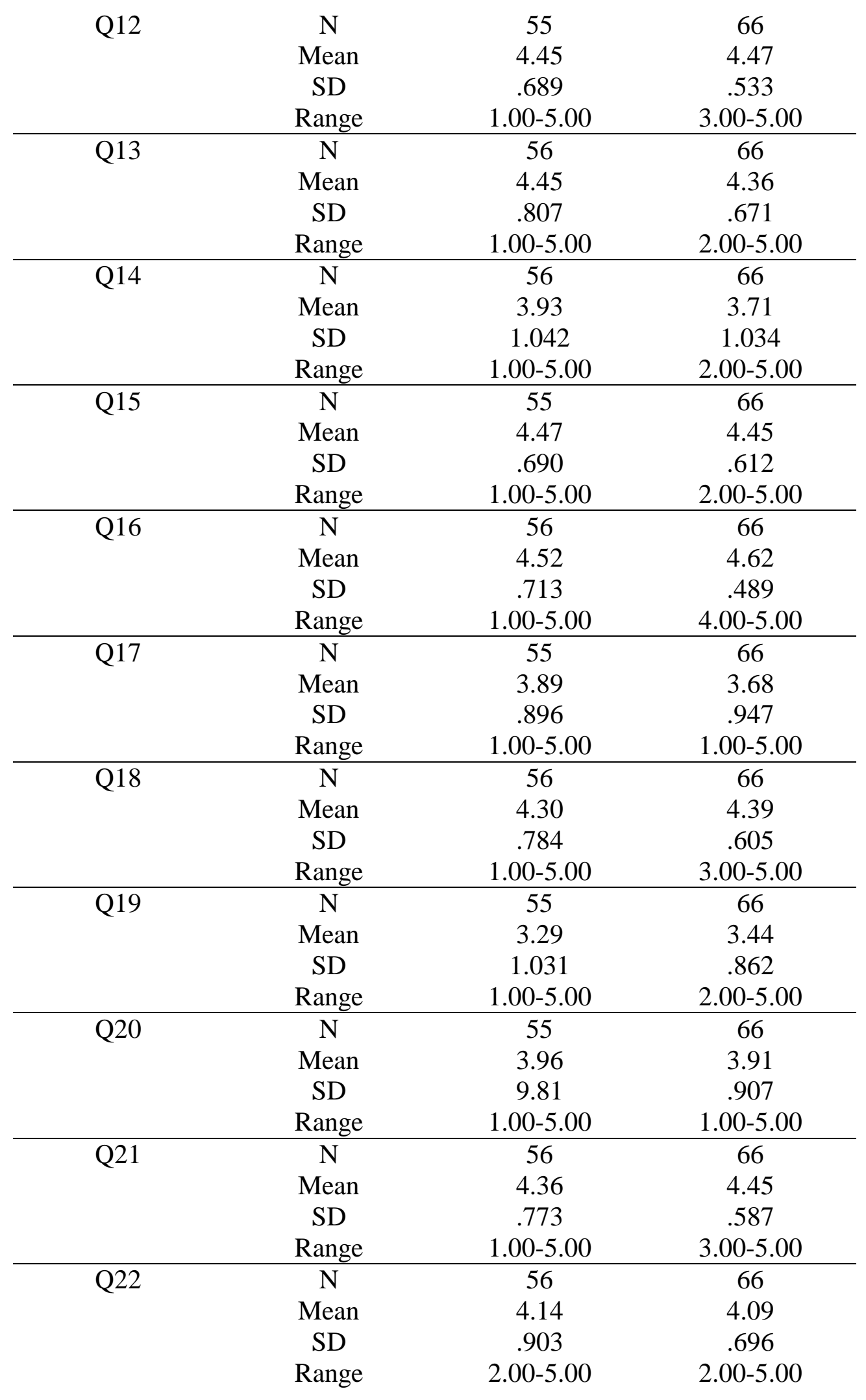




\begin{tabular}{|c|c|c|c|}
\hline Q23 & $\begin{array}{c}\mathrm{N} \\
\text { Mean } \\
\text { SD } \\
\text { Range }\end{array}$ & $\begin{array}{c}56 \\
3.39 \\
1.139 \\
1.00-5.00\end{array}$ & $\begin{array}{c}66 \\
2.82 \\
1.094 \\
1.00-5.00\end{array}$ \\
\hline Q24 & $\begin{array}{c}\mathrm{N} \\
\text { Mean } \\
\text { SD } \\
\text { Range }\end{array}$ & $\begin{array}{c}56 \\
3.05 \\
.961 \\
1.00-5.00\end{array}$ & $\begin{array}{c}66 \\
2.71 \\
1.004 \\
1.00-5.00\end{array}$ \\
\hline Q25 & $\begin{array}{c}\mathrm{N} \\
\text { Mean } \\
\text { SD } \\
\text { Range }\end{array}$ & $\begin{array}{c}56 \\
2.75 \\
1.049 \\
1.00-5.00\end{array}$ & $\begin{array}{c}66 \\
2.36 \\
.905 \\
1.00-4.00\end{array}$ \\
\hline Q26 & $\begin{array}{c}\mathrm{N} \\
\text { Mean } \\
\text { SD } \\
\text { Range }\end{array}$ & $\begin{array}{c}56 \\
3.70 \\
1.190 \\
1.00-5.00\end{array}$ & $\begin{array}{c}66 \\
3.39 \\
.990 \\
2.00-5.00\end{array}$ \\
\hline Q27 & $\begin{array}{c}\mathrm{N} \\
\text { Mean } \\
\text { SD } \\
\text { Range }\end{array}$ & $\begin{array}{c}56 \\
1.96 \\
.894 \\
1.00-5.00\end{array}$ & $\begin{array}{c}66 \\
1.86 \\
.782 \\
1.00-5.00\end{array}$ \\
\hline Q28 & $\begin{array}{c}\mathrm{N} \\
\text { Mean } \\
\text { SD } \\
\text { Range }\end{array}$ & $\begin{array}{c}56 \\
2.04 \\
.713 \\
1.00-5.00\end{array}$ & $\begin{array}{c}66 \\
2.02 \\
.620 \\
1.00-4.00\end{array}$ \\
\hline Q29 & $\begin{array}{c}\mathrm{N} \\
\text { Mean } \\
\text { SD } \\
\text { Range }\end{array}$ & $\begin{array}{c}56 \\
2.04 \\
.934 \\
1.00-5.00\end{array}$ & $\begin{array}{c}66 \\
2.00 \\
.823 \\
1.00-4.00\end{array}$ \\
\hline Q30 & $\begin{array}{c}\mathrm{N} \\
\text { Mean } \\
\text { SD } \\
\text { Range }\end{array}$ & $\begin{array}{c}56 \\
4.23 \\
.831 \\
1.00-5.00\end{array}$ & $\begin{array}{c}66 \\
4.21 \\
.691 \\
2.00-5.00\end{array}$ \\
\hline
\end{tabular}


Table 4

Frequency Distribution for Current and Past Mentor Split by Gender

\begin{tabular}{ccc}
\hline Current Mentor & Male & Female \\
Yes & 17 & 31 \\
No & 38 & 35 \\
Total & 55 & 66 \\
\hline Previous Mentor & Male & Female \\
Yes & 41 & 42 \\
No & 10 & 10 \\
Total & 56 & 66 \\
\hline
\end{tabular}


Table 5

Reported Roles of Current and Previous Mentors

\begin{tabular}{|c|c|c|}
\hline & Frequency & Percentage \\
\hline \multicolumn{3}{|l|}{ Current Mentor } \\
\hline Head Athletic Trainer & 18 & 11.9 \\
\hline HS Athletic Trainer & 2 & 1.3 \\
\hline Program Director & 4 & 2.6 \\
\hline College Athletic Trainer & 1 & .7 \\
\hline Athletic Trainer & 4 & 2.6 \\
\hline Doctor/Team Doctor & 3 & 2.0 \\
\hline Professor/Teacher & 5 & 3.3 \\
\hline Coach & 1 & .7 \\
\hline Co-Worker & 2 & 1.3 \\
\hline Assistant Athletic Trainer & 1 & .7 \\
\hline Assistant Principal & 1 & .7 \\
\hline Friend & 1 & .7 \\
\hline Sports Medicine Director & 1 & .7 \\
\hline Multiple Roles & 13 & 8.6 \\
\hline Missing & 94 & 62.3 \\
\hline \multicolumn{3}{|l|}{ Previous Mentor } \\
\hline Head Athletic Trainer & 33 & 21.9 \\
\hline HS Athletic Trainer & 2 & 1.3 \\
\hline Program Director & 6 & 4.0 \\
\hline College Athletic Trainer & 2 & 1.3 \\
\hline Athletic Trainer & 6 & 4.0 \\
\hline Doctor/Team Doctor & 1 & .7 \\
\hline Professor/Teacher & 1 & .7 \\
\hline Coach & 1 & .7 \\
\hline Co-Worker & 2 & 1.3 \\
\hline Assistant Athletic Trainer & 4 & 2.6 \\
\hline Friend & 5 & 3.3 \\
\hline Sports Medicine Director & 1 & .7 \\
\hline Graduate Assistant & 1 & .7 \\
\hline Preceptor & 1 & .7 \\
\hline Multiple Roles & 13 & 8.6 \\
\hline Missing & 72 & 47.7 \\
\hline
\end{tabular}


Table 6.1

Descriptive Statistics for Similar Demographic Characteristics Split by Gender

\begin{tabular}{cccc}
\hline & & Male & Female \\
\hline Similar Ethnicity & $\mathrm{N}$ & 56 & 66 \\
& Mean & 1.96 & 1.86 \\
& SD & .894 & .782 \\
& Range & $1.00-5.00$ & $1.00-5.00$ \\
\hline Similar Age & $\mathrm{N}$ & 56 & 66 \\
& Mean & 2.04 & 2.02 \\
& SD & .713 & .620 \\
& Range & $1.00-5.00$ & $1.00-4.00$ \\
\hline Similar Gender & $\mathrm{N}$ & 56 & 66 \\
& Mean & 2.04 & 2.00 \\
& SD & .934 & .823 \\
& Range & $1.00-5.00$ & $1.00-4.00$ \\
\hline
\end{tabular}


Table 6.2

Frequency Distribution for Likert Scaled Responses: Similar Ethnicity

\begin{tabular}{ccc}
\hline & Male & Female \\
\hline Strongly Disagree & 18 & 21 \\
Disagree & 26 & 36 \\
Undecided & 9 & 7 \\
Agree & 2 & 1 \\
Strongly Agree & 1 & 1 \\
Total & 56 & 66 \\
\hline
\end{tabular}


Table 6.3

Frequency Distribution for Likert Scaled Responses: Similar Age

\begin{tabular}{ccc}
\hline & Male & Female \\
\hline Strongly Disagree & 9 & 11 \\
Disagree & 39 & 44 \\
Undecided & 6 & 10 \\
Agree & 1 & 1 \\
Strongly Agree & 1 & 0 \\
Total & 56 & 66 \\
\hline
\end{tabular}


Table 6.4

Frequency Distribution for Likert Scaled Responses: Similar Gender

\begin{tabular}{ccc}
\hline & Male & Female \\
\hline Strongly Disagree & 16 & 17 \\
Disagree & 28 & 37 \\
Undecided & 7 & 7 \\
Agree & 4 & 5 \\
Strongly Agree & 1 & 0 \\
Total & 56 & 66 \\
\hline
\end{tabular}


Table 7.1

Descriptive Statistics for Perceived Effect on Retention Split by Gender

\begin{tabular}{ccc}
\hline & Male & Female \\
$\mathrm{N}$ & 56 & 66 \\
Mean & 4.23 & 4.21 \\
$\mathrm{SD}$ & .831 & .691 \\
Range & $1.00-5.00$ & $2.00-5.00$ \\
\hline
\end{tabular}


Table 7.2

Frequency Distribution for Likert Scaled Responses: Effect on Retention

\begin{tabular}{ccc}
\hline & Male & Female \\
\hline Strongly Disagree & 1 & 0 \\
Disagree & 1 & 2 \\
Undecided & 5 & 4 \\
Agree & 26 & 38 \\
Strongly Agree & 23 & 22 \\
Total & 56 & 66 \\
\hline
\end{tabular}


Figure 1

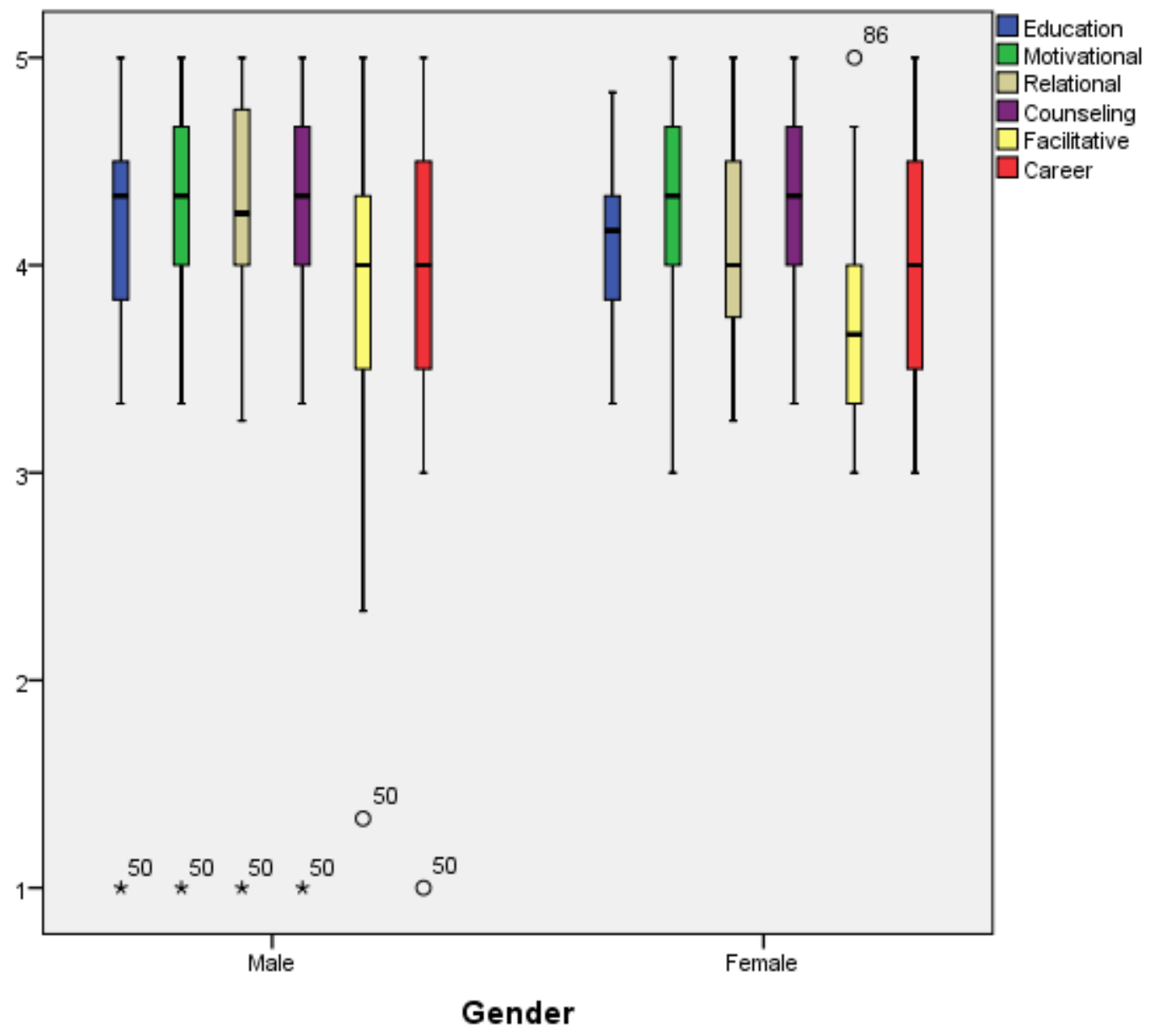

Figure 1. Box plot for ATSPME subscale responses compared by gender. 
Figure 2.1

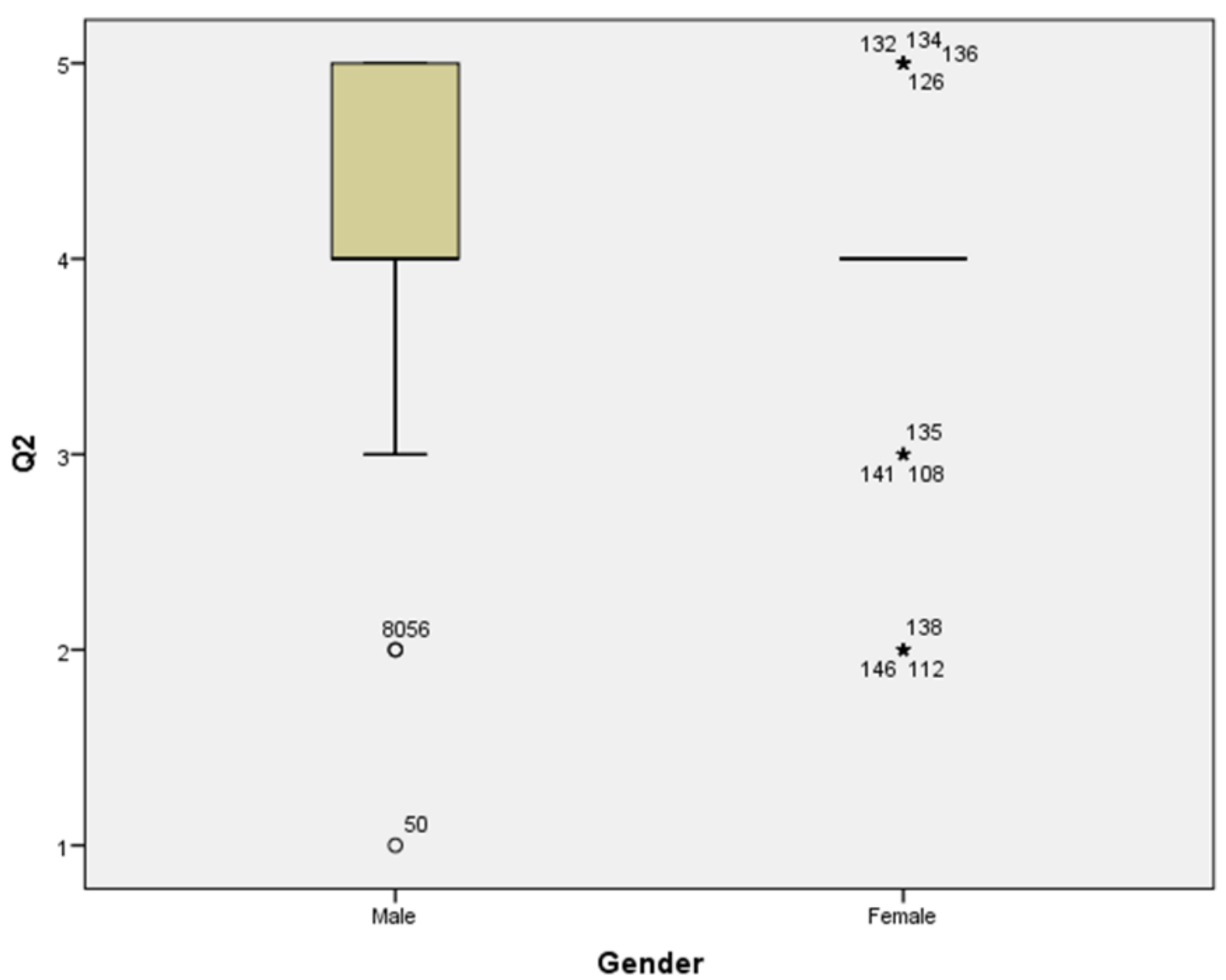

Figure 2.1. Box plot for Q2 of ATSPME split by gender. 
Figure 2.2

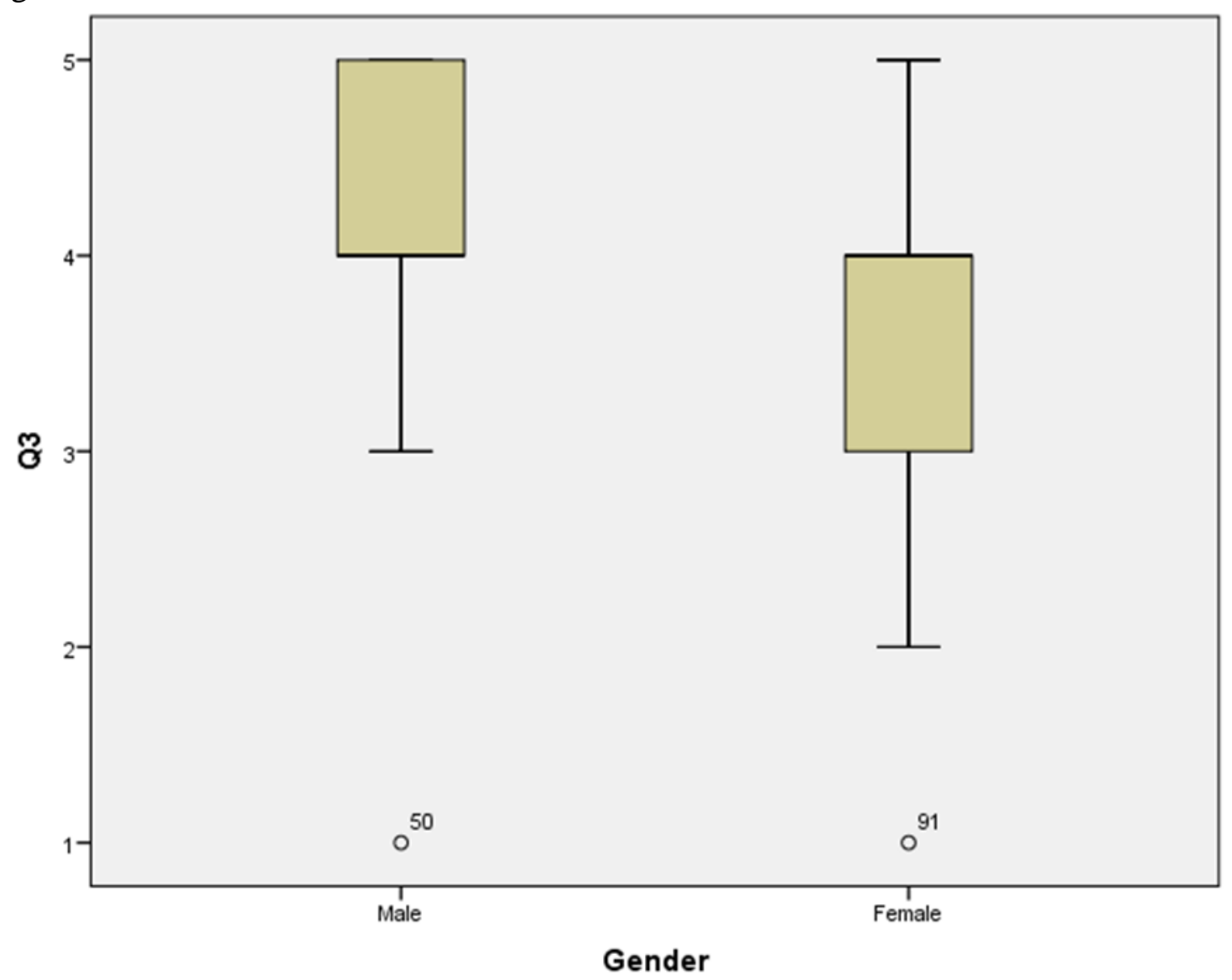

Figure 2.2. Box plot for Q3 of ATSPME split by gender. 
Figure 2.3

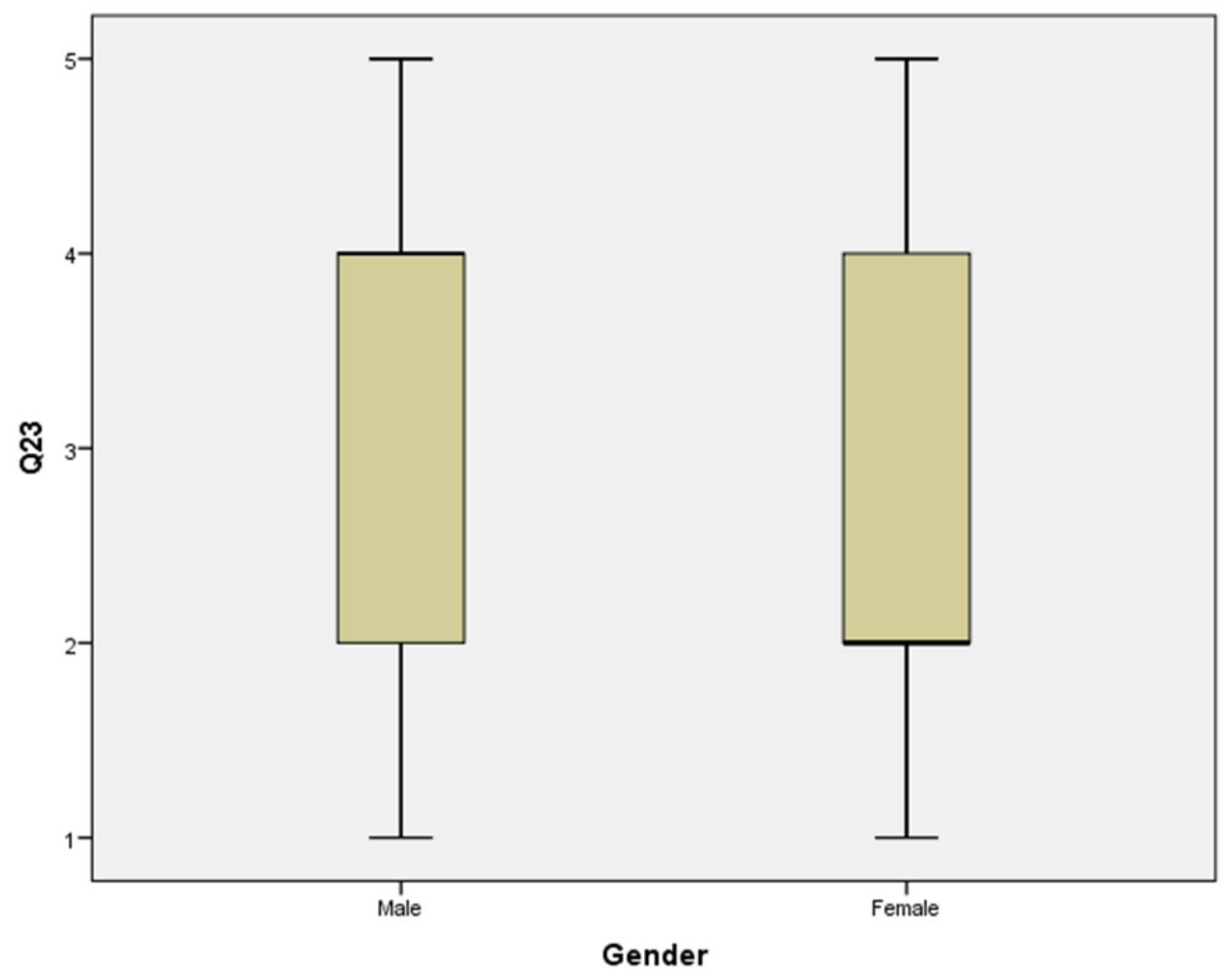

Figure 2.3. Box plot for Q23 of ATSPME split by gender. 
Figure 2.4

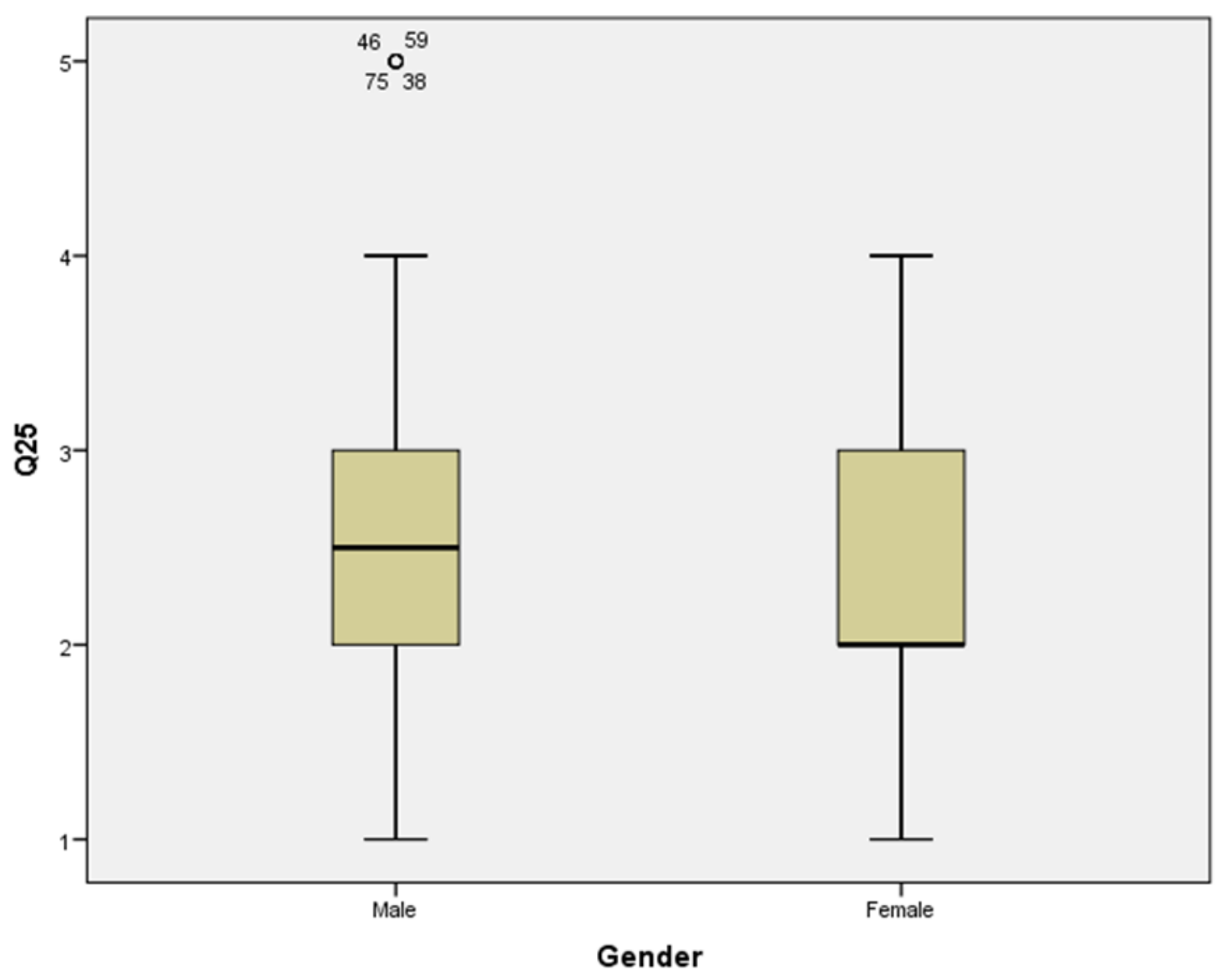

Figure 2.4. Box plot for Q25 of ATSPME split by gender. 
Figure 3.1

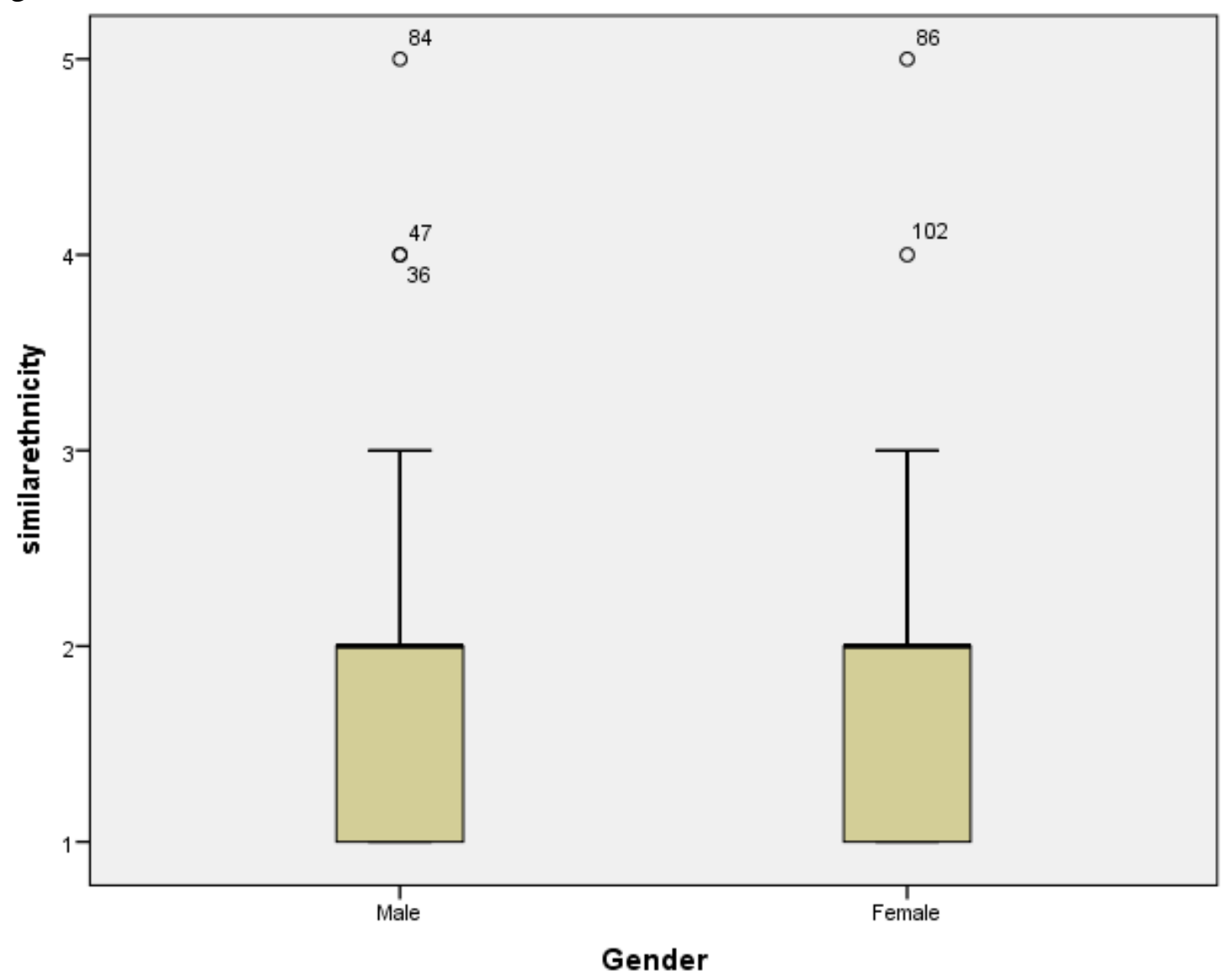

Figure 3.1. Box plot for importance of similar ethnicity of mentor and protégé split by gender. 
Figure 3.2

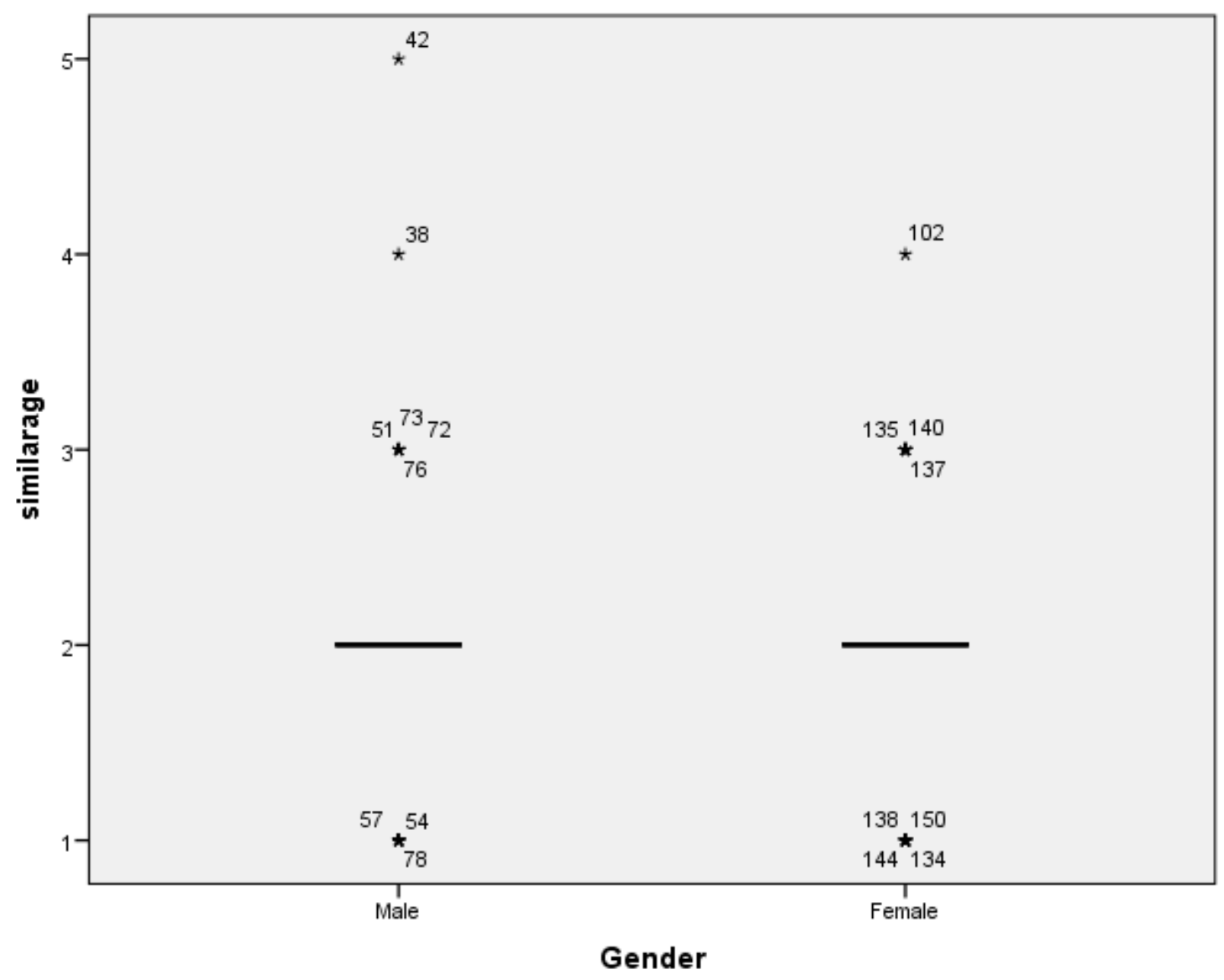

Figure 3.2. Box plot for importance of similar age of mentor and protégé split by gender. 
Figure 3.3

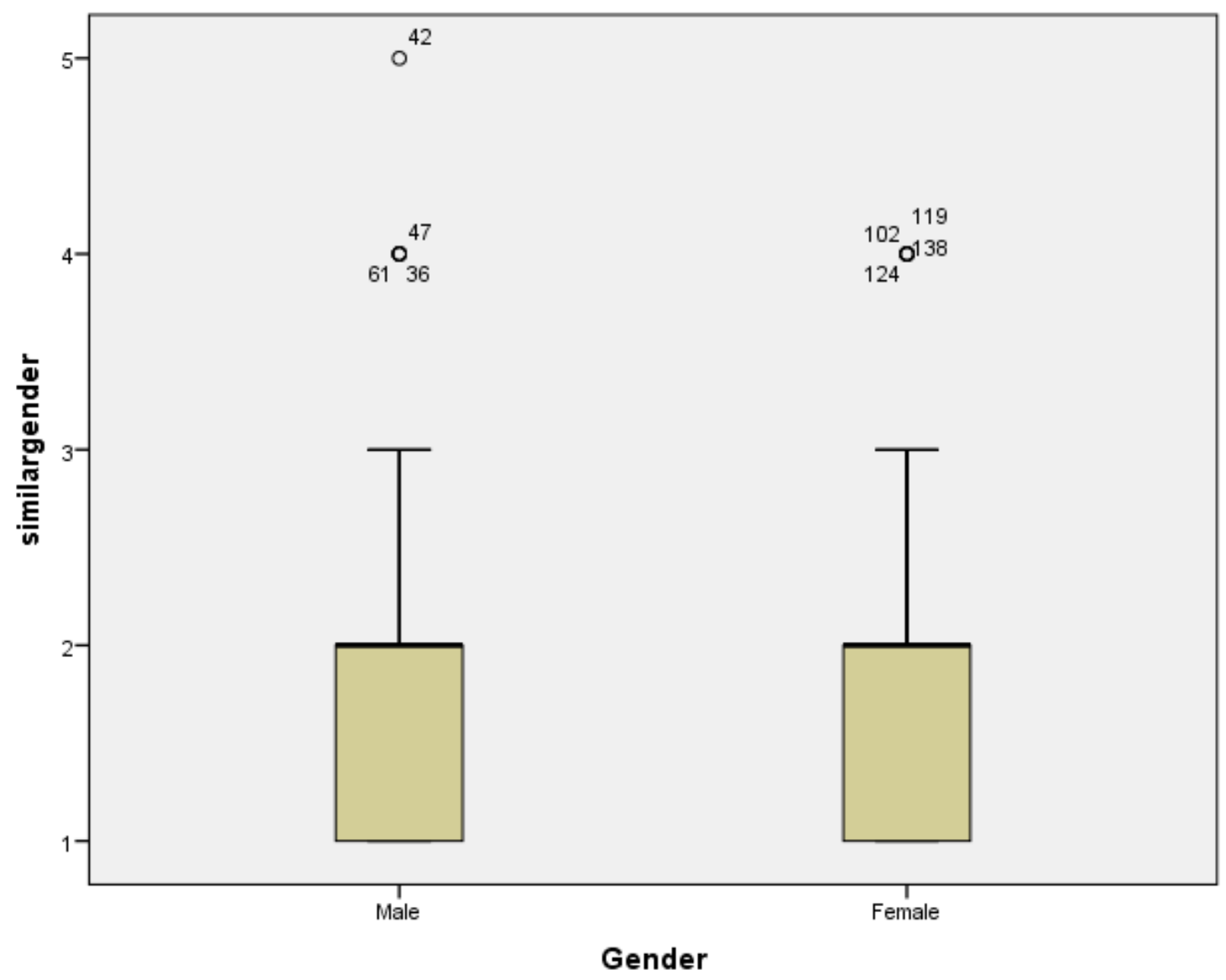

Figure 3.3. Box plot for importance of similar gender of mentor and protégé split by gender. 
Figure 4

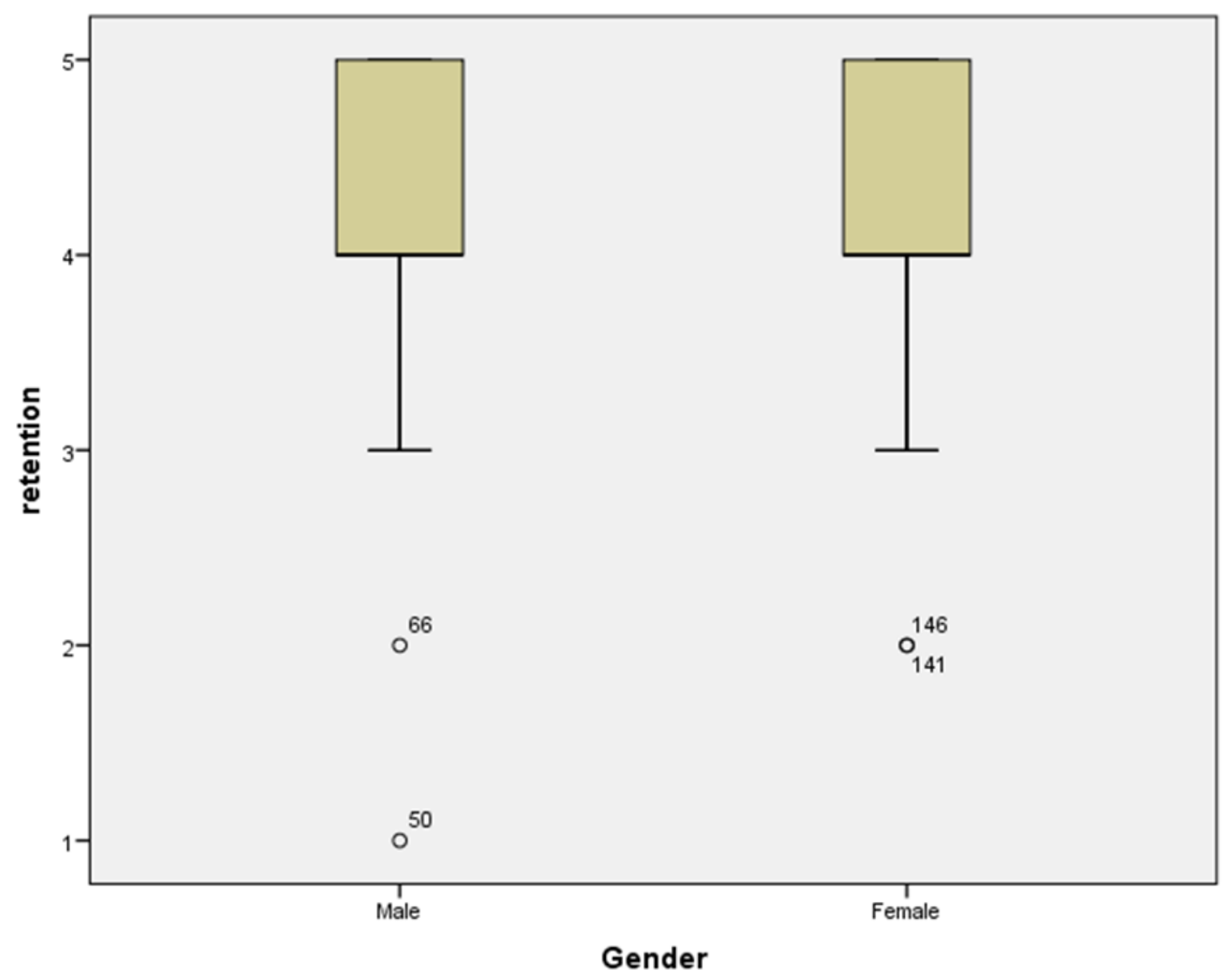

Figure 4. Box plot for perceived effect of mentoring on retention split by gender. 


\title{
Appendix A
}

\author{
Informed Consent
}

IRB

University of St. Augustine for Health Sciences

Out of Town: 1-855-384-9965 x 3151; Local: 1-512-394-9766 × 3151

IRB Informed Consent Form, IRB \# Site of Research: Online

Title: Examination of Athletic Trainers' Perceptions on Mentoring Relationships

Principle Investigator:

Nicole A. Wilkins, MS, LAT, ATC

400 Anacua Loop

Manchaca, TX 78652

210-392-4875

n.wilkins@usa.edu

Co-investigator(s):

Mr. Chuck Kimmel, MA, LAT, ATC

1 University Circle

St. Augustine, FL 32086

828-262-3100

kimmelcw@appstate.edu

Dr. Jordan Utley, PhD, LAT, ATC

1 University Circle

St. Augustine, FL 32086

214-250-0349

jutley@usa.edu

Funding Source: No funding source exists for this research.

Description of the Study:

The purpose of this research study is to examine the attitudes towards effective mentoring within the profession of athletic training, specifically within the secondary school setting of District 6 (Texas and Arkansas) of the National Athletic Trainers' Association. This district has been selected due to the unique nature of the structure of employment at the secondary school level. Athletic training in the secondary school system within the state of Texas are often set up with two co-head athletic trainers, one of each gender, which allows for mentoring to occur within the individual secondary schools. The state of Arkansas does not employ this design in their secondary schools. Since both states utilize different employment designs, mentoring relationships may differ as a result.

As a participant, you will be asked to complete a brief online survey about the characteristics of effective mentors and your attitude towards mentoring. The survey consists of 30 questions, with two additional open-ended section to provide additional commentary. All 
questions will be completed online and your answers will be recorded. This survey should take 10-15 minutes to complete in its entirety.

Benefits and Risks to the Participant: This is a minimal risk study. There are no direct benefits to you.

Costs and Payments to the Participant: There is no cost to you beyond the time and effort required to complete the procedures described above. There is no payment for participating in this study.

The University of St. Augustine is not liable for any cost or compensations incurred as a result of participating in this study.

Principle Investigator:

Nicole A. Wilkins, MS, LAT, ATC

n.wilkins@usa.edu

$210-392-4875$

Co-investigator(s):

Mr. Chuck Kimmel, MA, LAT, ATC

kimmelcw@appstate.edu

828-262-3100

Dr. Jordan Utley, PhD, LAT, ATC

jutley@usa.edu

214-250-0349

IRB Chair:

Dr. Elizabeth Ardolino, PT, MPT, MS, PhD

eardolino@usa.edu

$512-394-9766 \times 3143$

Confidentiality: All information obtained in this study is strictly confidential unless disclosure is required by law. Confidentiality will be maintained through eliminating your identifying information from the surveys. You will create a unique identity using the following formula: first 2 letters from first name, first 2 letters from last name, and year of birth (last two digits) and report this in the designated area of the survey. For example, Nicole Wilkins's unique ID would be NIWI83. Individual results will not be presented.

For the surveys delivered via survey monkey, please note the following: "The data may be accessed by a third party (i.e., owner of the survey software or intercepted during transmission. However, investigators are taking every precaution to keep your information confidential."

Participant's Right to Withdraw from the Study: You may refuse to participate. You may change your mind about being in the study and withdraw any time after the study has started without penalty. 
Other Considerations: If you have any questions at any time, please feel free to ask.

Voluntary Consent by Participant: Participation in this research project is totally voluntary, and your consent is required before you can participate. See signature statement below.

\section{Investigator's claim:}

I have explained to the purpose of the research study, the procedures required, and the possible risks and benefits to the best of my ability.

Investigator's signature:

Date:

Investigator's printed name:

Participant's claim:

I have read this consent form (or it has been read to me) and I fully understand the contents of this document and voluntarily consent to participate. All of my questions concerning this research have been answered. If $I$ have any questions in the future about this study, the investigator listed above or his/her staff will answer them. A copy of this form has been given to me and $I$ am at least 18 years of age at the time of reading and signing this document.

Participant's signature

Participant's printed name
Date

\section{Date}

Witness's printed name 


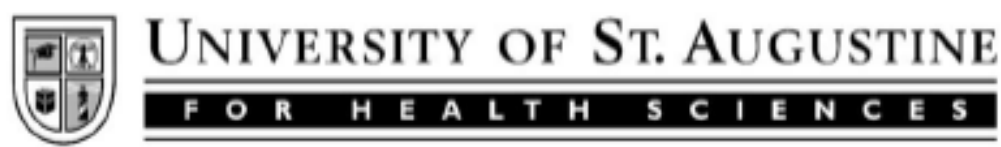

$9 / 01 / 2017$

Nicole Wilkins

400 Anacua Loop

Manchaca, TX 78652

210-392-4875

RE: EDD-0801-227 “Examination of Athletic Trainers' Perceptions on Mentoring Relationships"

Dear Ms. Wilkins:

The Chair of the Institutional Review Board (IRB), responsible for the review of research involving human subjects, has reviewed your original proposal, noted the revisions provided by you upon the reviewers' request and approved the revised project referenced above. Approval for the project will be for one year, starting September 1, 2017

If a University of St. Augustine For Health Sciences faculty member or student leaves the University prior to completion of a USAHS IRB-approved study, the study may be continued until expiration of that IRB approval. The IRB approval will expire on August 31, 2018.

This approval is granted with the understanding that no changes may be made in the procedures to be followed, nor in the consent form(s) to be used, until after such modifications have been submitted to the IRB for review and approval. Please be sure your consent form includes the IRB contact name and telephone number (Dr. Elizabeth Ardolino, Chair, University of St. Augustine for Health Sciences Institutional Review Board, 512-394-9766 ext. 3143, eardolino@usa.edu). Researchers must retain a copy of the signed consent form in their files for three years following completion of the project and must provide a copy of the consent form to the subject(s).

Any unanticipated problems involving risks to human subjects or serious adverse effects must be promptly reported to the IRB.

Prior to the expiration of this approval, you will receive notification of the need for updated information to be used for the project's continuing review. When project is completed, please notify the IRB in writing. Thank you.

Sincerely,

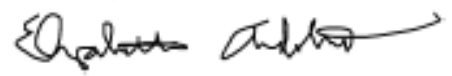

Elizabeth Ardolino, PT, PhD

Chair, IRB

Cc: Jordan|Utley, PhD, LAT, ATC \& Chuck Kimmel, MA, LAT, ATC 


\section{Appendix B}

\section{Athletic Training Students Perceptions of Mentoring Effectiveness (ATSPME)}

To Begin, please read the following definition of Mentoring, Mentor, and protégé and then answer question 1. Once this is completed, please read the directions for the remainder of the survey.

Mentoring: A one-one-one relationship whereby an experienced and concerned individual takes an interest in and actively helps a less experienced individual develop his/her potential.

Mentor: An experienced individual who is in a relationship with a protégé and assists in his/her development.

Protégé: A less experienced individual who is in a relationship with a mentor and benefits by developing his/her potential.

1. Do you currently have a mentor? Yes No (circle one)

If Yes, Who is, or who do you consider to be your mentor? (No names please, simply describe the individual--i.e., head athletic trainer, assistant athletic trainer, program director, coach, friend, classmate, etc...)

If No, have you ever had a mentor? Yes No (circle one).

If yes, Who (No names please, simply describe the individual--i.e., head athletic trainer, assistant athletic trainer, program director, coach, friend, classmate, etc...): 
Directions: Please read each numbered statement below and then circle the appropriate response (whether you agree or disagree) to the right. 5=strongly agree; $4=$ agree; $3=$ =undecided; $2=$ disagree; and 1=strongly disagree. Once you are finished, complete the open-ended question on the back.

\begin{tabular}{llccccc}
\hline & $\begin{array}{c}\text { Strongly } \\
\text { Agree }\end{array}$ & Agree & Undecided & Disagree & $\begin{array}{c}\text { Strongly } \\
\text { Disagree }\end{array}$ \\
\hline 2. & $\begin{array}{l}\text { Mentoring is more effective if I receive a } \\
\text { lot of information }\end{array}$ & 5 & 4 & 3 & 2 & 1
\end{tabular}

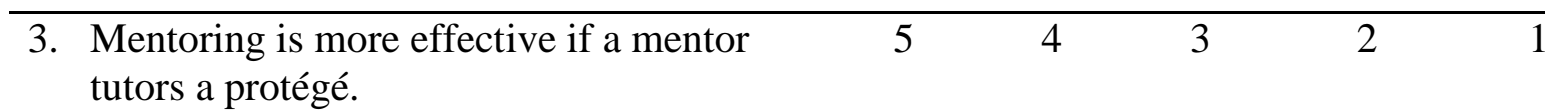

4. An effective mentor gives feedback to a

$\begin{array}{lllll}5 & 4 & 3 & 2 & 1\end{array}$
protégé about his/her performance as a professional.

5. An effective mentor is a good role model.

5
6. An effective mentor needs to be a good communicator.

7. An effective mentor should facilitate brainstorming and stimulate ideas.
8. An effective mentor encourages a protégé.

$\begin{array}{lllll}5 & 4 & 3 & 2 & 1\end{array}$

$\begin{array}{lllll}5 & 4 & 3 & 2 & 1\end{array}$

9. An effective mentor is inspirational.

$\begin{array}{lllll}5 & 4 & 3 & 2 & 1\end{array}$
10. An effective mentor rejuvenates a protégé.

\begin{tabular}{|c|c|c|c|c|c|}
\hline 11. Effective mentors befriend a protégé. & 5 & 4 & 3 & 2 & 1 \\
\hline $\begin{array}{l}\text { 12. An effective mentor is supportive of a } \\
\text { protégé. }\end{array}$ & 5 & 4 & 3 & 2 & 1 \\
\hline
\end{tabular}

\begin{tabular}{llllll}
\hline 13. Effective mentoring is based on trust. & 5 & 4 & 3 & 2 & 1 \\
\hline 14. Mentoring is more effective if a mentor & 5 & 4 & 3 & 2 & 1
\end{tabular}
and protégé share the same professional values and beliefs.

\begin{tabular}{llllll}
\hline 15. An effective mentor gives helpful advice. & 5 & 4 & 3 & 2 & 1 \\
\hline 16. Effective mentoring requires good & 5 & 4 & 3 & 2 & 1
\end{tabular}
listening skills. 


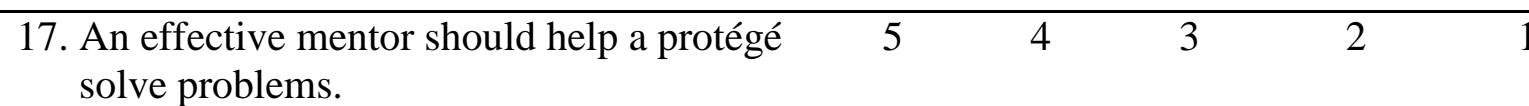

18. Effective mentors challenge their

$5 \quad 4$
protégés.

$\begin{array}{llll}4 & 3 & 2 & 1\end{array}$

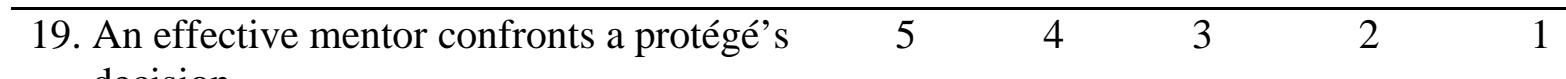
decision

20. Effective mentors test a protégé's

knowledge and skill.

\begin{tabular}{llllll}
\hline 21. An effective mentor helps a protégé & 5 & 4 & 3 & 2 & 1
\end{tabular}
network with other professionals.

\begin{tabular}{llllll}
\hline 22. Effective mentors expose protégés to & 5 & 4 & 3 & 2 & 1
\end{tabular}
potential employers.

23. Mentoring is effective if a mentor is available to a protégé on a daily basis.

24. Mentoring is more effective when a protégé is allowed to pick who mentors them.

25. Mentoring is more effective when it is monitored by a faculty member or administrator.

26. Mentoring is more effective when a mentor is significantly more experienced than the protégé.

27. Mentoring is more effective when a mentor is the same ethnicity as the protégé.

28. Mentoring is more effective when the mentor and the protégé are of similar ages.

$\begin{aligned} & \text { 29. Mentoring is more effective when a } \\ & \text { mentor is the same gender. }\end{aligned}$
$\begin{aligned} & \text { 30. Effective mentoring can have an effect on } \\ & \text { a protégé's retention in a given } \\ & \text { profession. }\end{aligned}$




\section{Please complete the open-ended question below}

Please provide any thoughts you may have about the process of mentoring that may not be captured in the questions listed above.

Please provide any thoughts as to attributes of successful, as well as unsuccessful, mentoring relationships you may have had.

Thank you for your responses.

\section{Demographic Information}

Age

Gender You Identify With (circle one) M $\quad$ F $\quad$ Other

Years of Service

Credentials:

State In Which You Are Employed (circle one) Arkansas Texas

\section{Ethnicity}

African American

American Indian

Asian American

Caucasian/White

Hispanic/Latino

Other:

\section{Educational Background}

Please indicate the highest level of education completed

High School

— Undergraduate

_ Graduate School

—_ Post-Graduate Work (EdD, PhD, etc)

\section{Licensure/Certification}

Please indicate your route to licensure/certification

— CAATE Accredited

Internship
Unsure

Copyright (C 2002 by William A. Pitney, EdD, ATC/L \&Greg G. Ehlers, MSEd, ATC/L 